\title{
MECHANICAL PROPERTIES AND MODELING OF SEAL-FORMING LITHOLOGIES APR 301992
}

\author{
A. K. Kronenberg, J. E. Russell, N. L. Carter, \\ W. Ibanez, and R. Mazariegos \\ Center for Tectonophysics \\ Texas A\&M Úniversity \\ College Station, TX 77843 \\ (409) 845-3251
}

Technical Progress Report Number 2

March 15, 1991 - March 14, 1992

Apri1 1992

\author{
PREPARED FOR THE U.S. DEPARTMENT OF ENERGY \\ UNDER GRANT NUMBER DE-FG87ER13711 \\ Texas A\&M Research Foundation Project No.5746A-02 \\ Start Date: 15 September 1990 \\ Completion Date: 14 September 1993 \\ Texas $A$ and $M$ Research Foundation \\ Box 3578 \\ College Station, TX 77843
}

DIGTAIBUTION OF THIS DOCUMENT IS UNLUMITEC DISCLAIMER

\footnotetext{
This report was prepared as an accuunt of work sponsored by an agency of the United States Government. Neither the United States Government nor any agency thereof, nor any of their employees, makes any warranty, express or implied, or assumes any legal liability or responsibility for the accuracy, completeness, (r) usefulness of any information, apparatus, product, or process disclosed, or represents that its use would not infringe privately owned rights. Reference herein to any specific commercial product, process, or service by trade name, trademark, manufacturer, or otherwise does not necessarily constitute or imply its endorsement, recommendation, or favoring by the United States Government or any agency thereof. The views and opinions of authors expressed herein do not necessarily state or reflect ihose of the Unitau Siäica Govinament or any agency therenf
}
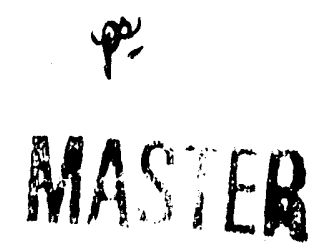


\section{TABLE OF CONTENTS}

DOE FORM 1332.16

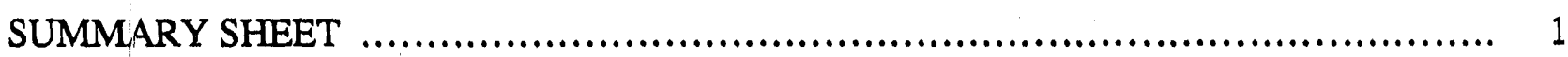

Accomplishments During Period March 15, 1991 to March 14, 1992 ................... 1

Continued Research Support ....................................................... 2

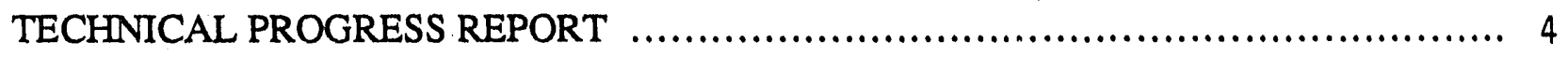

Project Objectives ................................................................ 4

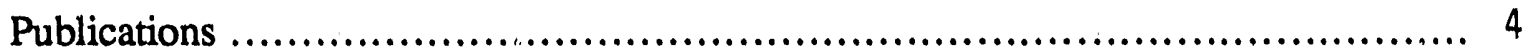

Mechanical Properties of Shale .................................................... 6

Shale Characterization............................................................. 7

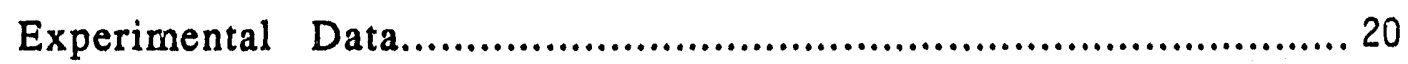

Mechanical Modeling of the Growth of Salt Structures ................................. 33

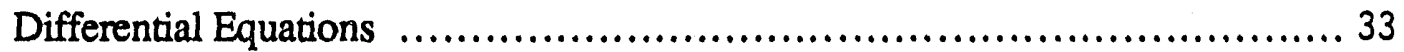

Mesh Layout and Variables Placement ......................................... 34

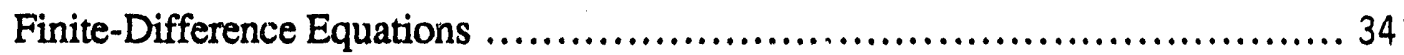

Pressure Correction ........................................................... 34

Free Surface Tracking ...................................................... 37

Steady-State Flow of Rocksalt ............................................. 37

Results and Validation .................................................... 38

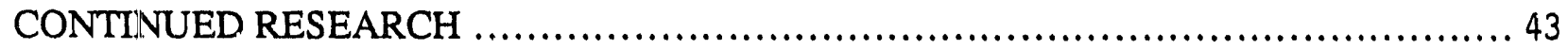

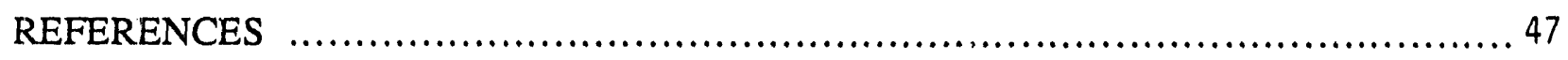

APPENDIX 


\section{SUMMARY SHEET}

\section{Mechanical Properties and Modeling of Seal-Forming Lithologies DE-FG87ER13711}

\section{Accomplishments During Period March 15, 1991 to March 14, 1992}

Our work on the deformation of mica-bearing rocks has been completed over the project period, March 15, 1991 to March 14, 1992, and significant progress has been made towards the description of the mechanical properties of an illite-bearing shale and modeling the evolution of salt structures subjected to depositional loads. Support for this research contributed to the completion of a first rate Ph.D. thesis by W. T. Shea, who defended and graduated in December, 1991, and is now employed at Exxon Production Research. His first manuscript (see Appendix) resulting from this work has been accepted for publication in the Joumal of Geophysical Research (Solid Earth), and the second will appear, by invitation, in the Festschrift for John Christie in the Journal of Structural Geology. Progress and results of our research of shale deformation and modeling of salt structures are summarized as follows:

1. The mineralogy, particle sizes, clay preferred orientations, intergranular textures, and water content of the first shale used for this study (an illite-bearing shale from Louisiana) have been characterized by a variety of methods, including powder X-ray diffraction and infrared (IR) absorption measurements, $\mathrm{X}$-ray goniometry, weight loss measurements, and optical and high resolution transmission electron microscopy (TEM). The clay preferred orientations of the other shale starting materials have been measured. These materials come from cores taken in the Appalachian and Illinois basins and are currently stored in a controlled humidity chamber.

2. The deformation of shale, composed of illite, quartz, feldspar, kaolinite and chlorite, with $1.8 \mathrm{w} \% \mathrm{H}_{2} \mathrm{O}$ in the clay interlayers, has been investigated in constant strain rate experiments performed at confining pressures $\mathrm{P}_{\mathrm{c}}$ of up to $250 \mathrm{MPa}$, temperatures $\mathrm{T}$ from $21^{\circ}$ to $200^{\circ} \mathrm{C}$, and strain rates $\dot{\varepsilon}$ from $2.2 \times 10^{-4}$ to $2.3 \times 10^{-7} \mathrm{~s}^{-1}$.

3. Over this range of conditions, we have determined its mechanical anisotropy by loading samples parallel, perpendicular, and at $45^{\circ}$ to bedding and examined this anisotropy as a function of confining pressure.

4. The rate and temperature dependencies of shale deformation have been determined from strain rate- and temperature-stepping experiments, respectively, performed at conditions that promote stability of structured, interlayer water in this material. We have used these results to examine the base-line mechanical behavior of shale in the absence of pore fluids and determined values of $Q$ and $\alpha$, assuming an exponential law of the form $\dot{\varepsilon}=\mathrm{A} \exp \left\{\alpha\left(\sigma_{1}-\sigma_{3}\right)\right\} \exp (-\mathrm{Q} / \mathrm{RT})$. The results are 
remarkably similar to parameter determinations for mica schist deformed by dislocation glide and kinking.

5. A finite difference code in Fortram 77 has been developed to model the development of salt structures by solving the incompressible Navier-Stokes equations in two dimensions using primitive variables (u,v,p). An Eularian grid (mesh) is used.

6. To keep track of the free surface (interface between salt and overburden) the volume fraction advection method is used. The numerical model calculates the growth rates of a gravitational instability with less than $2 \%$ error for low viscosity cases. However, the velocity--pressure linked algorithm needs to be refined, since growth rates are over predicted by $30 \%$ for large viscosity cases.

7. The results of our long-term experiments on Avery Island rocksalt, deformed at constant strain rates of down to $10^{-9} \mathrm{~s}^{-1}$ at temperatures of $50^{\circ}$ and $100^{\circ} \mathrm{C}$ (experiments that were successfully completed during this project period after continuous operation for 3.5 and 3.6 years), reveal a change in mechanism and a new power law creep equation more appropriate to natural deformations than earlier constitutive relations determined over shorter times. Incorporation of this relationship into our numerical model and comparison of the results with salt structures where seismic reflection and stratigraphic relationships provide constraints on the timing of deformation may allow us to extend this relationship to natural deformation rates.

\section{Continued Research Support}

We still have much to investigate, both in our studies of shale deformation and mobile salt tectonics. We plan to examine the effects of water on shale deformation, both in the form of layered water in clay interlayers and as a free pore fluid. Initial tests using a low temperature oven and controlled humidity chamber indicate that we are able to manipulate the initial water content of samples prior to deformation. We will begin by deforming samples with varying concentrations of interlayer water, followed by experiments that over-step the swelling pressure of this material to examine the effects of pore fluids. In our modeling studies, we will develop computer algorithms that integrate different rheological models into our master finite difference program. Among the rheological constitutive models to be used are:

a. The new power law recently evaluated at low strain rates for Avery Island rocksalt (Carter, in prep.).

b. The steady-state law for fluid-assisted creep of rocksalt (Spiers et al., 1990). 
c. A preliminary non-linear law for shale may be incorporated for the host rocks surrounding deforming salt bodies, once material parameters are determined from the experiments.

The influence of temperature on deformation rates in our model will be included by calculating the geothermal gradient as a function of geologic time, solving the heat conduction equation in twodimensions. Finally, the numerical model will be applied to selected salt structures from the Gulf of Mexico and the results compared with known stratigraphic loading histories and cross-cutting relationships that record structural development. 


\section{TECHNICAL PROGRESS REPORT}

\section{Project Objectives}

Both rocksalt and shale lithologies are actively deformed in response to gravitational loads associated with deposition, and both form effective seals to petroleum and natural gas. Thus, the shapes of seal-forming units, and the nature of fractures and faults that may breach them depend upon either the mechanical properties of salt or those of shale, and the loading histories to which they have been subjected.

The objectives of this research include the determination of the mechanical properties under controlled conditions of well-characterized shales, and the numerical modeling of rocksalt (and eventually shale) formations using laboratory-based rheologies. Progress has been made towards these goals over this project period, both in our experimental program on shale deformation and model development for the growth of salt diapirs. The mechanical anisotropy of an illite-bearing shale from Louisiana has been determined and related to the preferred orientation and distribution of clays. Its strength in the absence of pore fluids has been determined at confining pressures of up to $250 \mathrm{MPa}$ and at high pressure we have investigated the effects of deformation rate and temperature. The results for this shale with 1.8 weight $\% \mathrm{H}_{2} \mathrm{O}$ within clay interlayers are similar to results obtained for mica-bearing schist.

A numerical finite difference code has been developed to solve the incompressible NavierStokes equations and validated using a two-layer linear viscous model for which analytic solutions are available. Comparison of the numerical results with analytic solutions of Chandrasakhar for two infinite half-spaces and solutions of Ramberg for two finite layers with fixed top and bottom boundaries indicate errors of only $2 \%$ for low viscosity cases $\left(10^{-5}\right.$ to $\left.10^{2} \mathrm{~Pa}-\mathrm{s}\right)$. Departures from the analytic solutions of $25-30 \%$ have been observed for high viscosity cases $\left(10^{15}-10^{22} \mathrm{~Pa}-\mathrm{s}\right)$. Although the code has only been validated for the linear viscous case, it is capable of solving for highly nonlinear constitutive laws as well as solving for arbitrary interfaces between the salt and overburden.

\section{Publications}

Our paper on the deformation of an isotropic mica schist has been accepted for publication in the Joumal of Geophysical Research and appears in the Appendix. A second manuscript on the strength and anisotropy of schists with varying mica contents will soon be submitted to the Journal of Structural Geology in a special issue dedicated to John Christie. We have submitted an abstract 
for publication in EOS Trans. AGU and will present our results for shale at the upcoming Spring AGU Meeting in Montreal.

Included below are the citations and abstracts to these publications.

Shea, W. T., and Kronenberg, A. K. (1992) Rheology and deformation mechanisms of an isotropic mica schist, J. Geophys. Res., 27 (in press).

Abstract: We have investigated the transitional, semi-brittle deformation of a mica schist $\left(\sim 75 \%\right.$ biotite) by shortening cylinders cored at $0^{\circ}, 45^{\circ}$, and $90^{\circ}$ to foliation to varying strains, at confining pressures $P_{c}$ to $500 \mathrm{MPa}$, constant strain-rates $\dot{\varepsilon}$ from $1.5 \times 10^{-7}$ to $1.6 \times 10^{-4} \mathrm{~s}^{-1}$, and temperatures $T$ from $25^{\circ}$ to $400^{\circ} \mathrm{C}$. Deformation is concentrated within one or more throughgoing, mm-wide shear zones at all conditions; these localize at low strains $(\varepsilon<2 \%)$ through the nucleation and coalescence of dense sets of intragranular micro-kink bands (MKBs). Despite distinct differences in the relative number of mica grains oriented favorably for slip and kinking in different loading directions, the differential stresses required for shear zone development vary little with fabric orientation. Biotite schist undergoes a transition from strain-softening to steady-strength mechanical response at confining pressures in the range 75 to $150 \mathrm{MPa}$. The pressure sensitivity of strength (characterizud by the slope $\mu$ of the Mohr envelope) decreases from $\mu \sim 0.5$ (at $P_{c}<100 \mathrm{MPa}$ ) to $\mu<$ 0.1 at pressures greater than $200 \mathrm{MPa}$, reflecting the increasing contribution of glide and kinking in biotite at higher pressures. However, dilatancy associated with microcracking and void formation along MKB boundaries persists to at least $500 \mathrm{MPa}$. Within the pressure-insensitive regime (200 5 $P_{c} \leq 500 \mathrm{MPa}$ ), temperature and strain rate dependencies of strength determined in stepping tests reveal a strong history dependence to flow that cannot strictly be described by a steady-state constitutive law. Samples deformed in steps from low to high temperatures or fast to slow strain rates consistently exhibit stronger temperature and strain rate sensitivities than those deformed along $T$-decreasing or $\dot{\varepsilon}$-increasing paths. Path-dependent effects may reflect differences in the degree to which inherited dislocation substructures are utilized or overprinted during later deformation increments. By assuming an exponential relationship between differential stress $\sigma_{d}$ and strain rate $\dot{\varepsilon}$ of the form $\dot{\varepsilon}=C \exp \left(\alpha \sigma_{\mathrm{d}}\right) \exp (-Q / R T)$, we fit the data with two end-member flow laws with a single activation energy $Q=89 \mathrm{~kJ} / \mathrm{mol}$, and exponential constants $\alpha_{\mathrm{ss}}=0.15 \pm 0.01 \mathrm{MPa}^{-1}$ and $\alpha_{w s}=0.55 \pm 0.04 \mathrm{MPa}^{-1}$ that account for the different responses observed along stepping paths that are strongly sensitive or weakly sensitive to $T$ and $\dot{\varepsilon}$, respectively. Application of the results to crustal deformation suggests that mica-rich aggregates are weaker than other common rock types throughout a broad mid-crustal depth range, supporting the inference that retrograde reaction to 
phyllosilicates may be imporiant in localizing crustal deformations within large faults and shear zones.

Ibanez, W. D., Kronenberg, A. K., and Wenk, H. R., (1992) Anisotropy and the brittle-ductile deformation of shale, EOS Trans. AGU, 73 (Submitted).

The deformation of a shale composed of illite, quartz, feldspar, kaolinite and chlorite, with 1.8 weight $\% \mathrm{H}_{2} 0$ in clay interlayers, has been investigated at confining pressures $\left(\mathrm{P}_{\mathrm{c}}\right)$ up to 250 $\mathrm{MPa}$, temperatures $(\mathrm{T})$ from $21^{\circ}, 200^{\circ} \mathrm{C}$, and constant strain rates $\dot{\mathrm{\varepsilon}}$ from $2.2 \times 10^{-4}$ to $2.3 \times 10^{-7} \mathrm{~s}^{-1}$. Triaxial compression experiments on samples cored parallel, perpendicular, and at $45^{\circ}$ to bedding reveal anisotropy in the strength of this shale that can be attributed to compositional layering and the preferred orientation of illite (001) planes, as determined by $\mathrm{X}$-ray goniometry. The highest differential stresses $\left(\sigma_{1}-\sigma_{3}=219 \mathrm{MPa}\right.$ at $\left.\mathrm{P}_{\mathrm{c}}=250 \mathrm{MPa}, \mathrm{T}=21^{\circ} \mathrm{C}, \dot{\varepsilon}=2.2 \times 10^{-4}\right)$ are measured for samples shortened parallel to bedding, with somewhat lower stresses measured perpendicular to bedding $\left(\sigma_{1}-\sigma_{3}=209 \mathrm{MPa}\right)$, while samples shortened at $45^{\circ}$ to bedding are weakest $\left(\sigma_{1}-\sigma_{3}=167\right.$ $\mathrm{MPa}$ ).

Deformation of shale is brittle at low pressures while transitional brittle-ductile behavior is observed at the higher pressures. Mohr envelopes for samples of all three orientations are non-linear. Apparent values of internal friction $\mu$ decrease, with increasing normal stress, from $\sim 0.36$ and $\sim 0.7$ $\left(\sigma_{\mathrm{n}}<150 \mathrm{MPa}\right)$ to $\sim 0.30\left(\sigma_{\mathrm{n}}=250 \mathrm{MPa}\right)$ for sampies loaded parallel and pexpendicular to bedding. Samples shortened at $45^{\circ}$ to bedding exhibit a weaker pressure dependence and $\mu$ varies from $\sim 0.7$ $\left(\sigma_{\mathrm{n}}<150 \mathrm{MPa}\right)$ to $\sim 0.18\left(\sigma_{\mathrm{n}}=250 \mathrm{MPa}\right)$. Strengths measured at $\mathbf{P}_{\mathrm{c}}=250 \mathrm{MPa}$ are weakly dependent on $\dot{\varepsilon}$ and T. Assuming a relationship $\dot{\varepsilon}=A \exp \left\{\alpha\left(\sigma_{1}-\sigma_{3}\right)\right\} \exp (-Q / R T)$ at a constant pressure, results of temperature- and strain rate-stepping experiments give values of $Q=69( \pm 10) \mathrm{kJ}$ $\mathrm{mol}^{-1}$ and $\alpha$ ranging from $0.29( \pm 0.04) \mathrm{MPa}^{-1}$ to $0.52( \pm 0.07) \mathrm{MPa}^{-1}$ depending upon orientation. While pressure dependent, presumably brittle processes continue to be important at this pressure, values of $Q$ and $\alpha$ for shales are comparable to those $\left(Q=89 \mathrm{~kJ} \mathrm{~mol}^{-1}\right.$ and $\left.\alpha=0.15 \mathrm{MPa}^{-1}\right)$ associated with glide and kinking in mica schist (Shea and Kronenberg, 1992).

\section{Mechanical Properties of Shale}

Our investigation of the mechanical properties of shales has thus far been focussed on establishing the behavior of an illite-bearing shale with a fixed concentration of water within clay interlayers, in the absence of a free pore fluid. We have used a wide vanety of methods to characterize the composition and texture of the starting material and have performed deformation experiments following a strategy similar to that used to study mica-bearing rocks. These data provide a means of comparing the mechanical responses of clay-bearing shales with mica-bearing schists and 
we ultimately plan to compare these data with shale samples with varying amounts of water, both within the clay interlayers and in intergranular pores.

\section{Shale Characterization}

The shale that we have chosen for study is part of the Wilcox formation and comes from core collected from West Baton Rouge Parish, Louisiana at depths of 3954.8 to $3960.3 \mathrm{~m}(12,975$ to 12,993 feet). It appears light to dark grey in color and bedding is apparent as layers of varying clay content and intermittent quartz-rich layers $\sim 1 \mathrm{~mm}$ in thickness. Parting along bedding is rare and the core remains relatively unfractured. Based on weighted averages of powder X-ray diffraction for several size fractions, this shale is made up primarily of illite/mica (40-50\%), kaolinite (5-10\%), quartz (30-40\%), feldspar (1-5\%), and chlorite (1-5\%) with small concentrations of smectites and/or mixed layer clays. The cementing minerals appear to be primarily quartz and aragonite.

The shale core was disaggregated, first mechanically using a mortar and pestle, and then chemically, removing carbonates with $\mathrm{NaOAc}$ and removing organic matter and $\mathrm{MnO}_{2}$ with $\mathrm{H}_{2} \mathrm{O}_{2}$. The sample was then partitioned into sand $(22.6 \%)$, silt $(59.1 \%)$, coarse clay (13.4\%), and fine clay (4.9\%) fractions by sieving and centrifugation by standard soils analysis techniques (Gibbs, 1965; Jackson, 1956; Klug and Alexander, 1954; Kunze, 1965; Mehsa and Jackson, 1960). Powder X-ray measurements were performed on the sand and silt fractions without further sample treatment. The cations of the clay fractions were exchanged with $\mathrm{K}$ and $\mathrm{Mg}$ using $1 \mathrm{~N}$ solutions of $\mathrm{KCl}$ and $\mathrm{MgCl}_{2}$. The clay fractions were then heated and glycerated and analyzed by X-ray diffraction in order to affect changes in the unit cell dimensions of swelling clays and aid in their identification.

The powder X-ray pattern measured for the sand fraction (Figure 1) is representative of the bulk sample material and includes reflections due to mica/illite, quartz, kaolinite, and chlorite. X-ray patterns of the clay fractions (Figure 2$)$ reveal a persisient $10 \AA$ peak $\left(2 \theta=8.53^{\circ}\right)$ following both heat treatments and glyceration due to illite and some detrital mica. Kaolinite is present as indicated by a $7 \AA$ peak $\left(2 \theta=12.38^{\circ}\right)$ and a second order $3.5 \AA$ peak $\left(2 \theta=24.86^{\circ}\right)$ that do not appear for samples exchanged with $\mathrm{K}$ and annealed at $550^{\circ} \mathrm{C}$. Quartz is apparent from $3.34 \AA$ and $4.7 \AA$ peaks $(2 \theta=$ $26.79^{\circ}$ and $20.87^{\circ}$ respectively). Chlor te has been identified from the $14 \AA$ peak $\left(2 \theta=6.04^{\circ}\right)$ that persists after heat treatment and glyceration, and appears most prominent after annealing at $550^{\circ} \mathrm{C}$. Smectites and/or mixed layer clays are suggested by a broad, poorly-defined 13-14 $\AA$ peak $(2 \theta \cong$ $\left.6.9^{\circ}\right)$. Based upon peak intensities and spectral separation and simulation routines (NEWMOD and MLXER), the coarse clay fraction is estimated to consist of illite/mica (30\%), chlorite (30\%), kaolinite $(20 \%)$, quartz (10\%), and smectite/mixed layer clays $(-10 \%)$. The fine clay fraction is estimated to consist of illite/mica (20\%), kaolinite (15\%), and smectite/mixed layer clays ( $65 \%)$.

The clay mineralogy was further constrained by measurements of total $\mathrm{K}_{2} \mathrm{O}$ and cation exchange capacity. Total $\mathrm{K}_{2} \mathrm{O}$ measurements of 4.37 and $2.82 \mathrm{wt} \%$ for the coarse and fine clay 


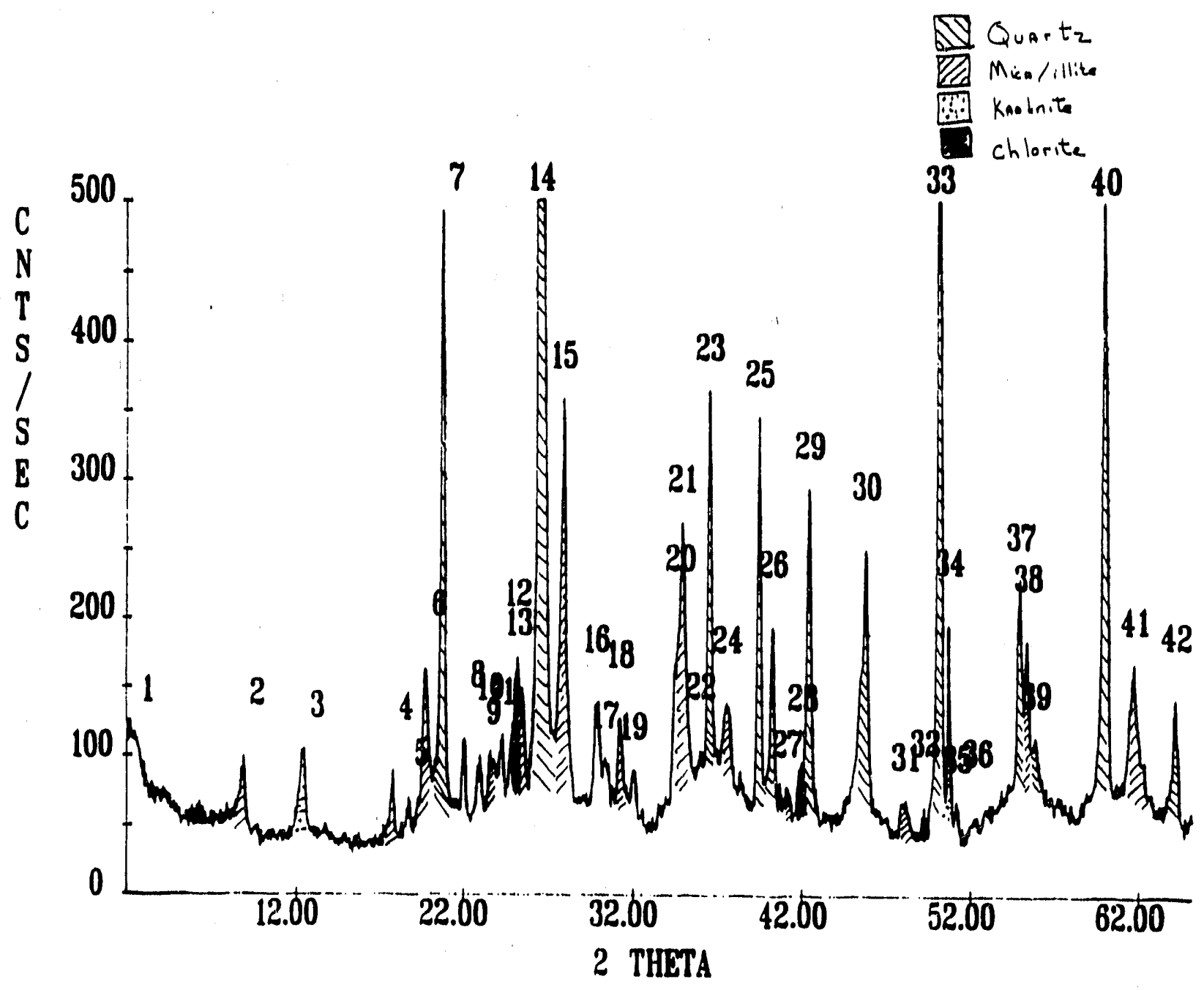

Figure 1. Powder X-ray diffraction of sand fraction of the Wilcox formation shale. 


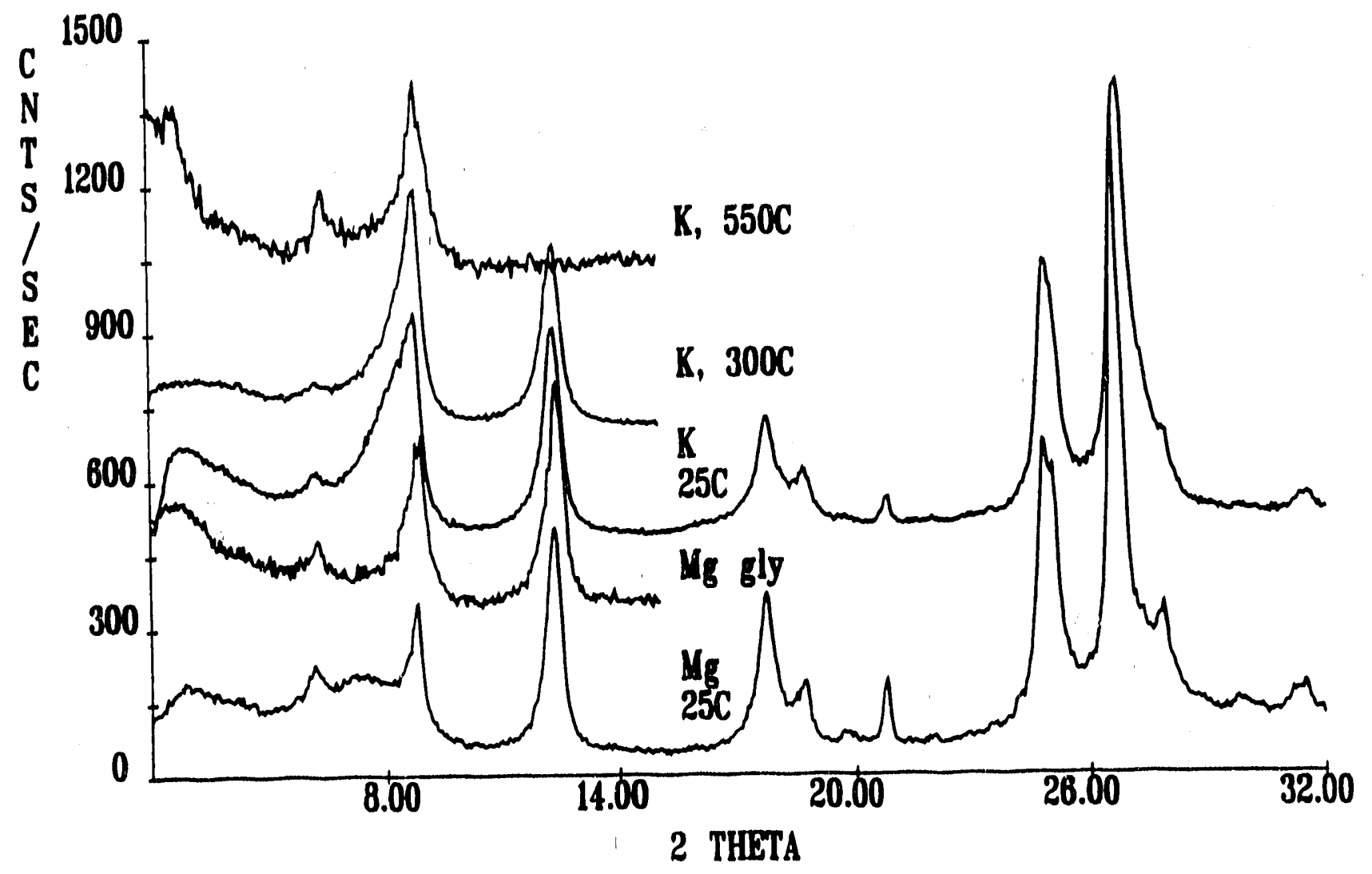

Figure 2. Powder X-ray diffraction of coarse clay fraction of Wilcox formation shale. 


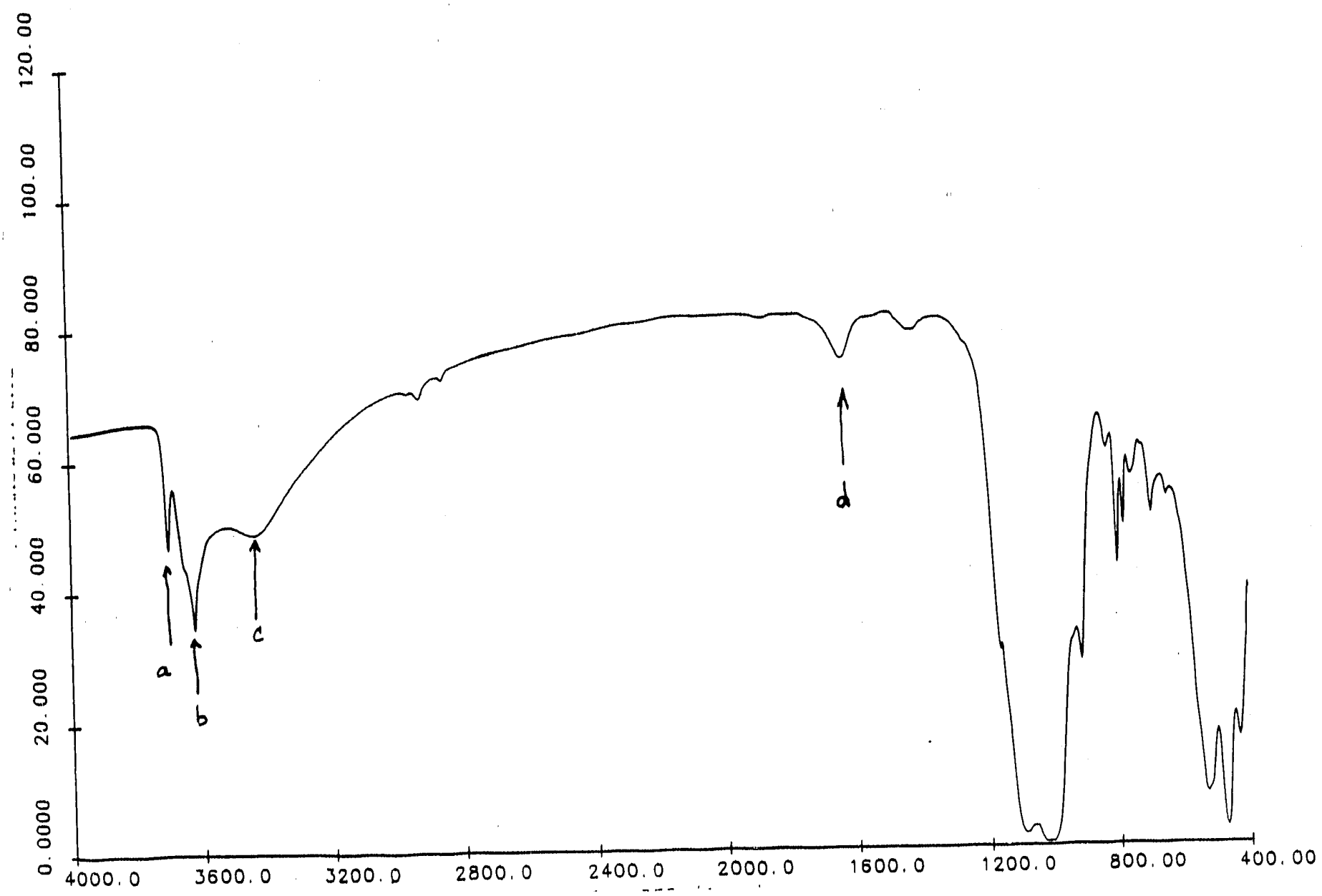

Figure 3. IR transmittance versus wavenumber for coarse clay powder sample embedded in $\mathrm{KBr}$ pellet. Bands $\mathrm{a}$ and $\mathrm{b}$ may be assigned to $\mathrm{OH}$ stretching of hydroxyl groups of illite and kaolinite. The broad bands $\mathrm{c}$ and $\mathrm{d}$ are assigned, respectively, to $\mathrm{OH}$ stretch and $\mathrm{HOH}$ bend modes of molecular water of smectites or possibly mixed-layer clays. 


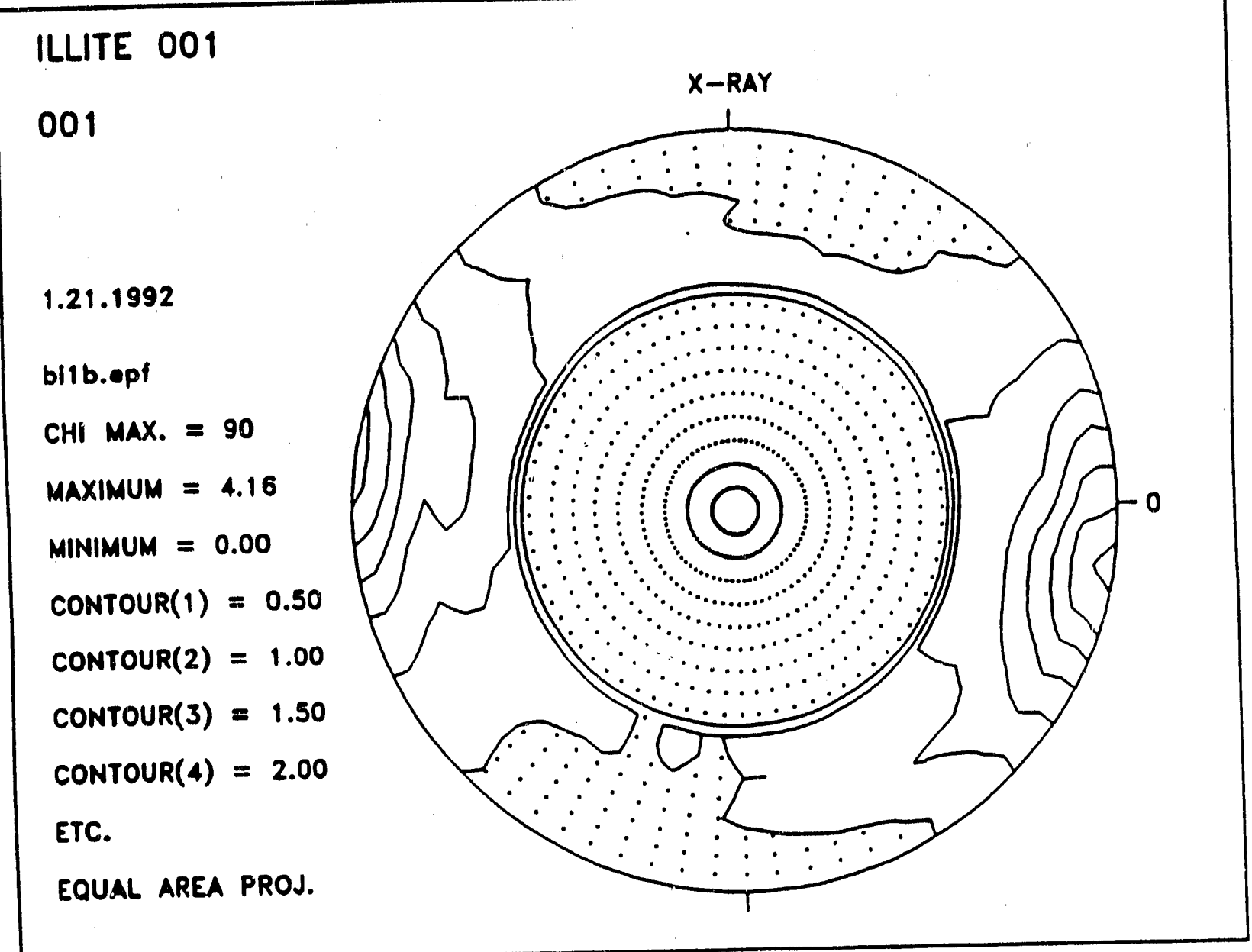

Figure 4. Contoured stereograph of the illite (001) reflection intensity, showing broad maxima perpendicular to the bedding orientation. The central (circular) region has not, as yet, been sampled and requires measurement of thin sections prepared orthogonal to this sample. 

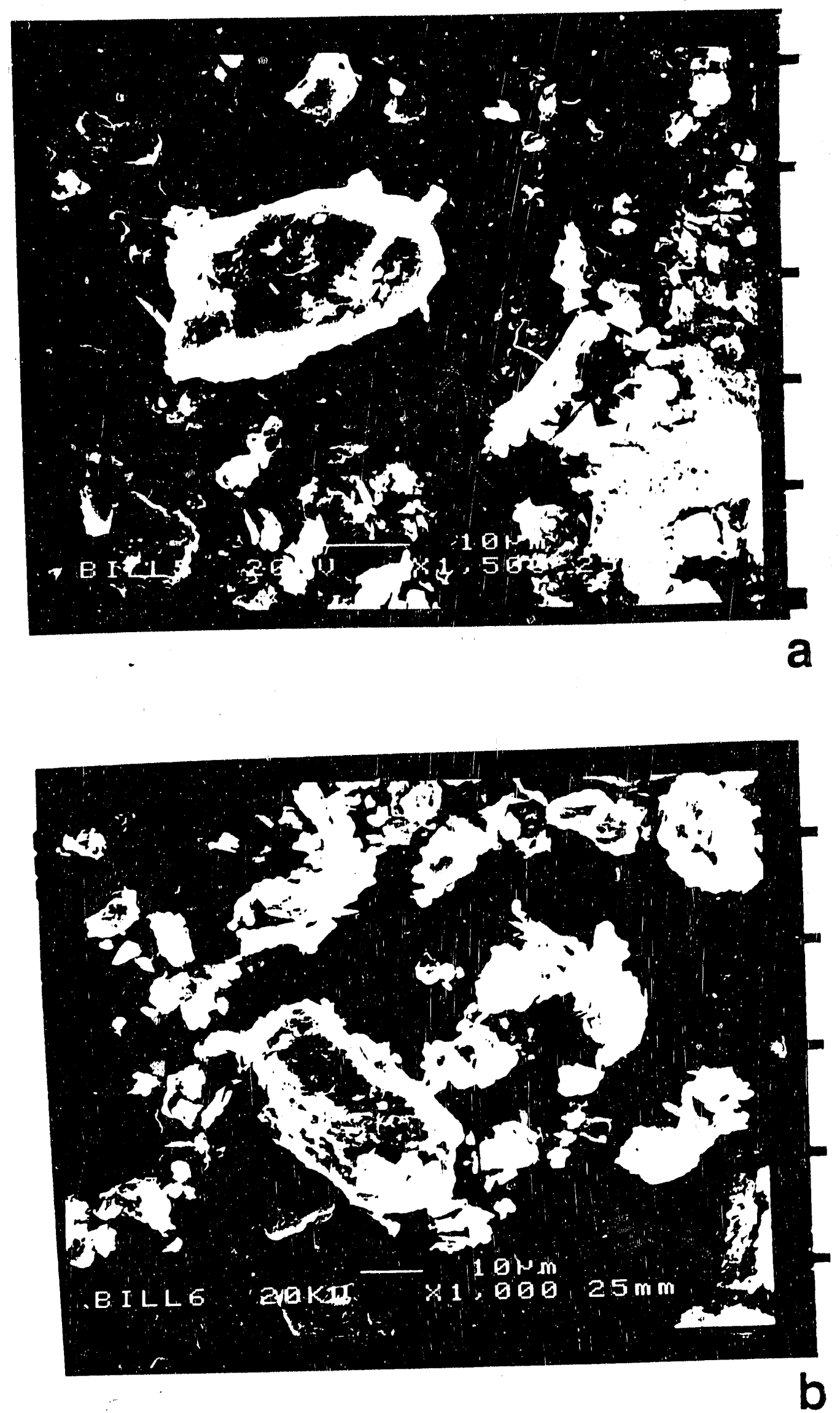

Figure 5. SEM micrographs of silica-cemented phyllosilicates withm sind racturi. 


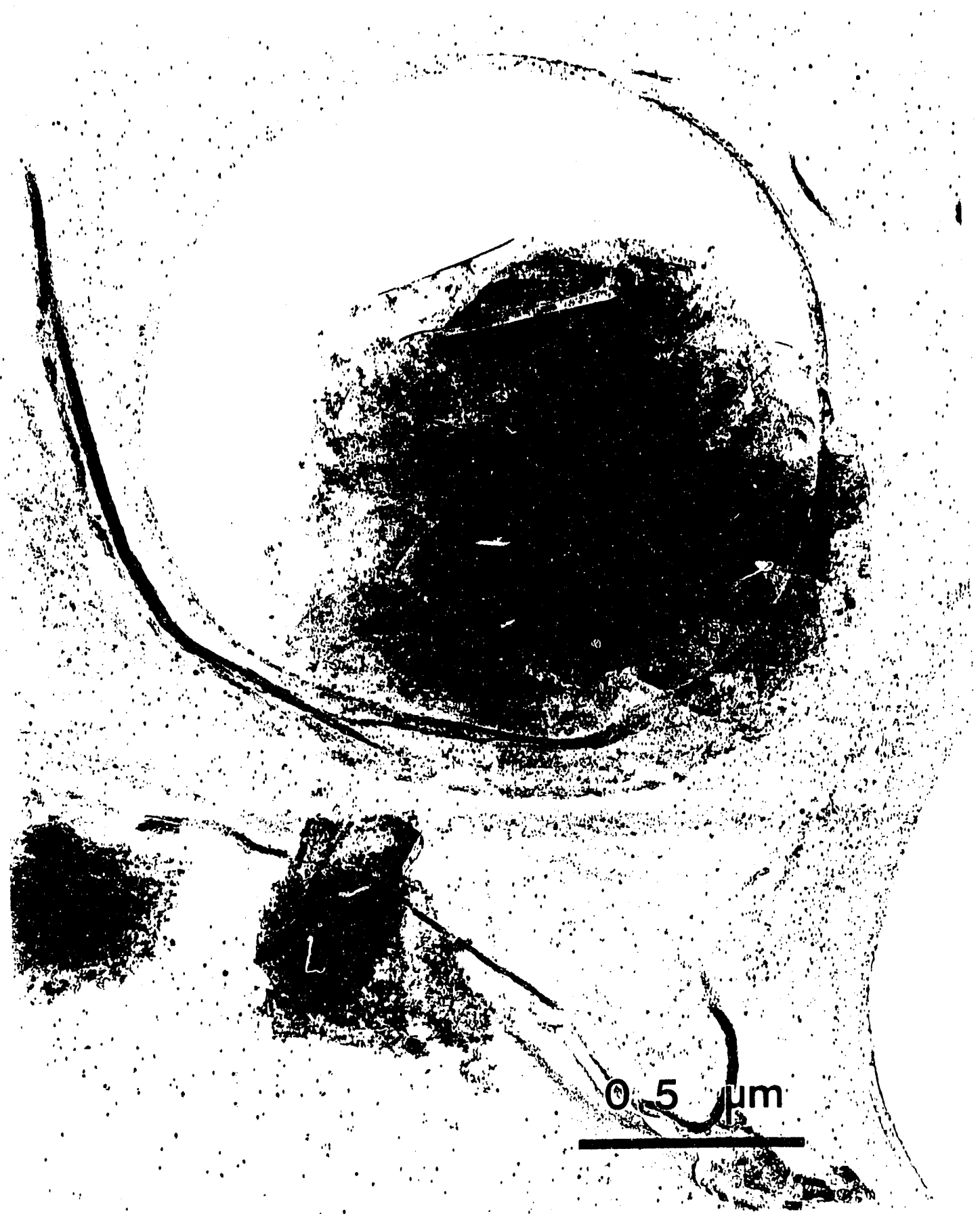

Figure 6. TEM micrograph showing tabular morphology characteristic of illite. Little or no evidence has been found for smectites on the basis of morphology. 


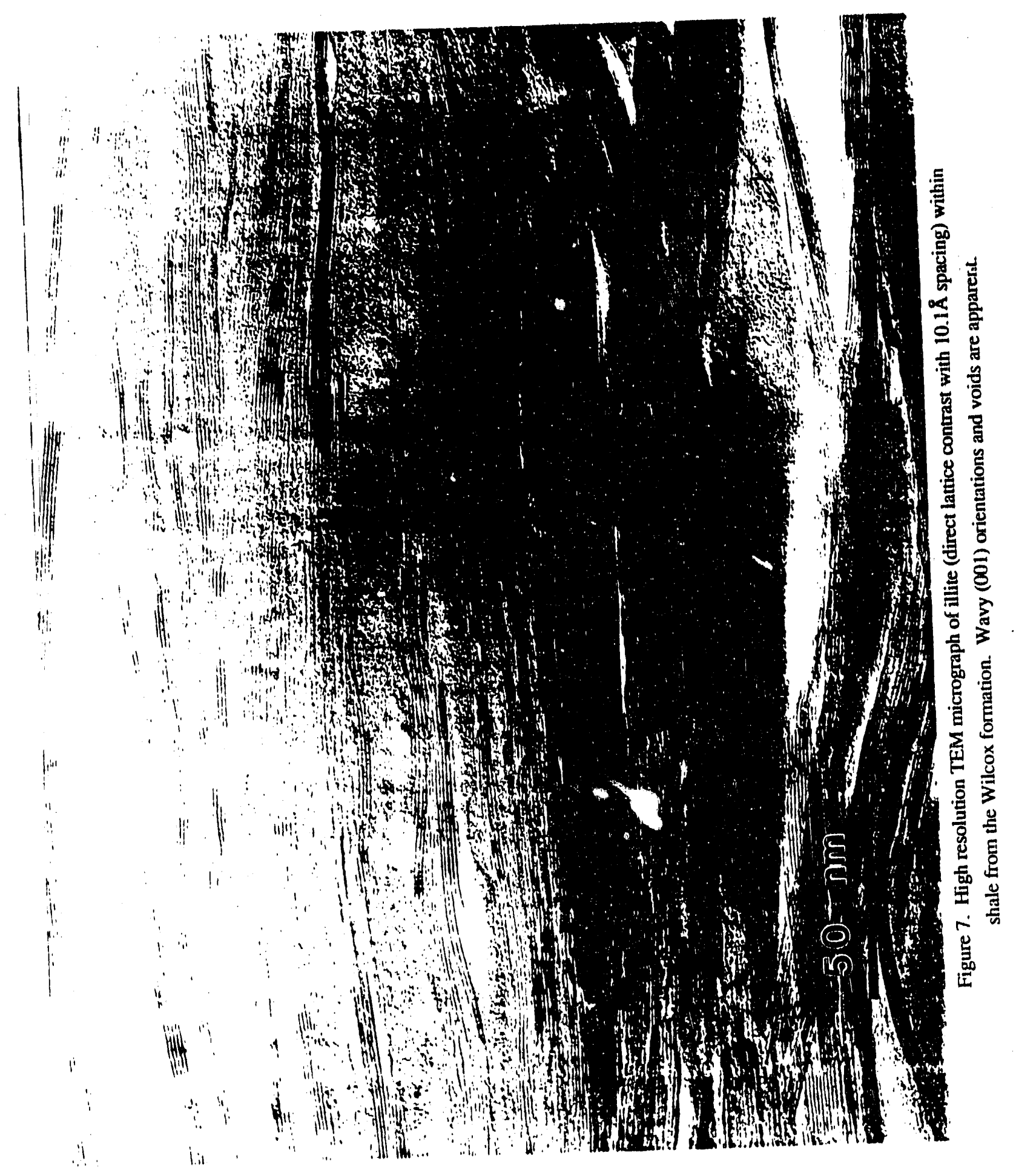




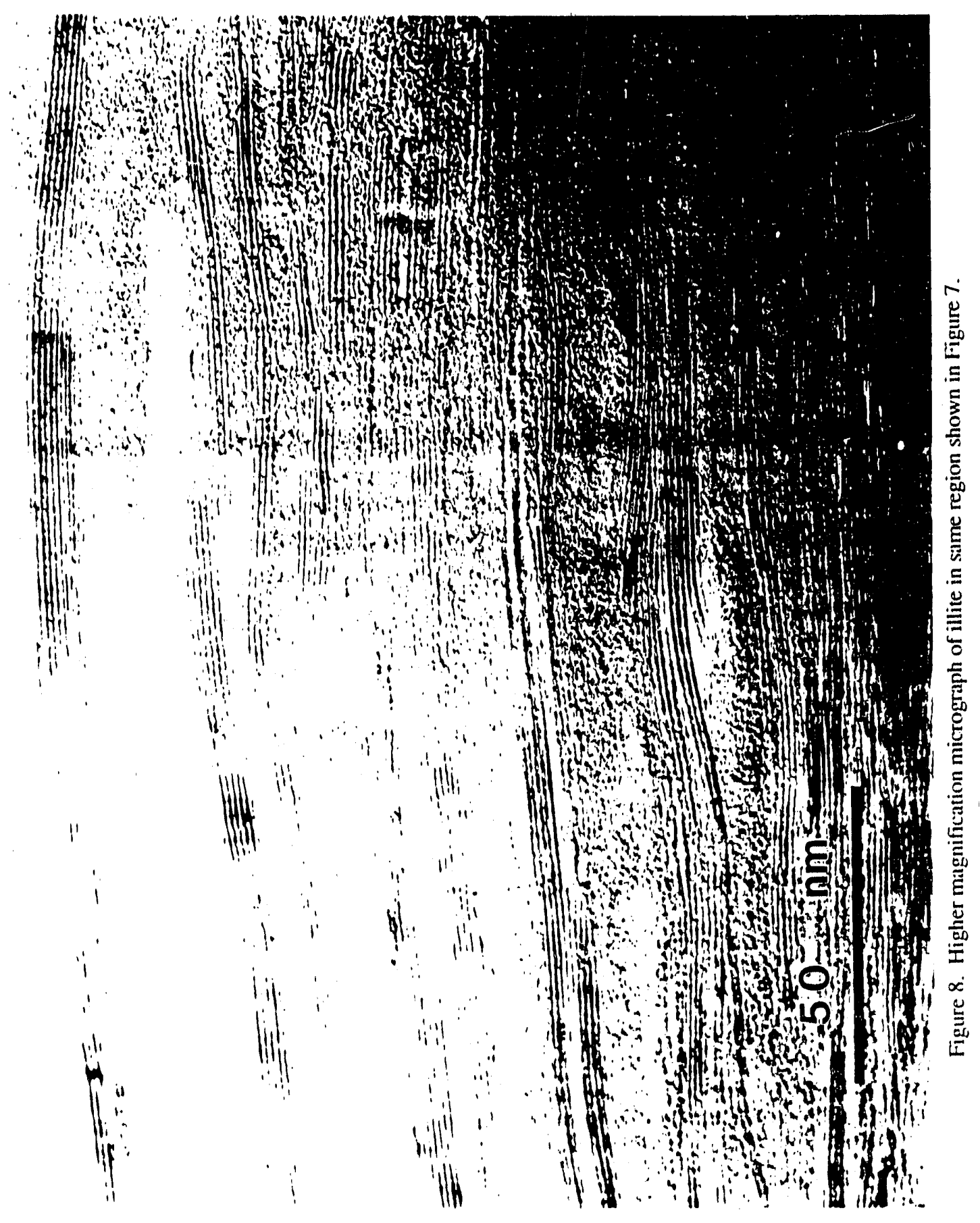




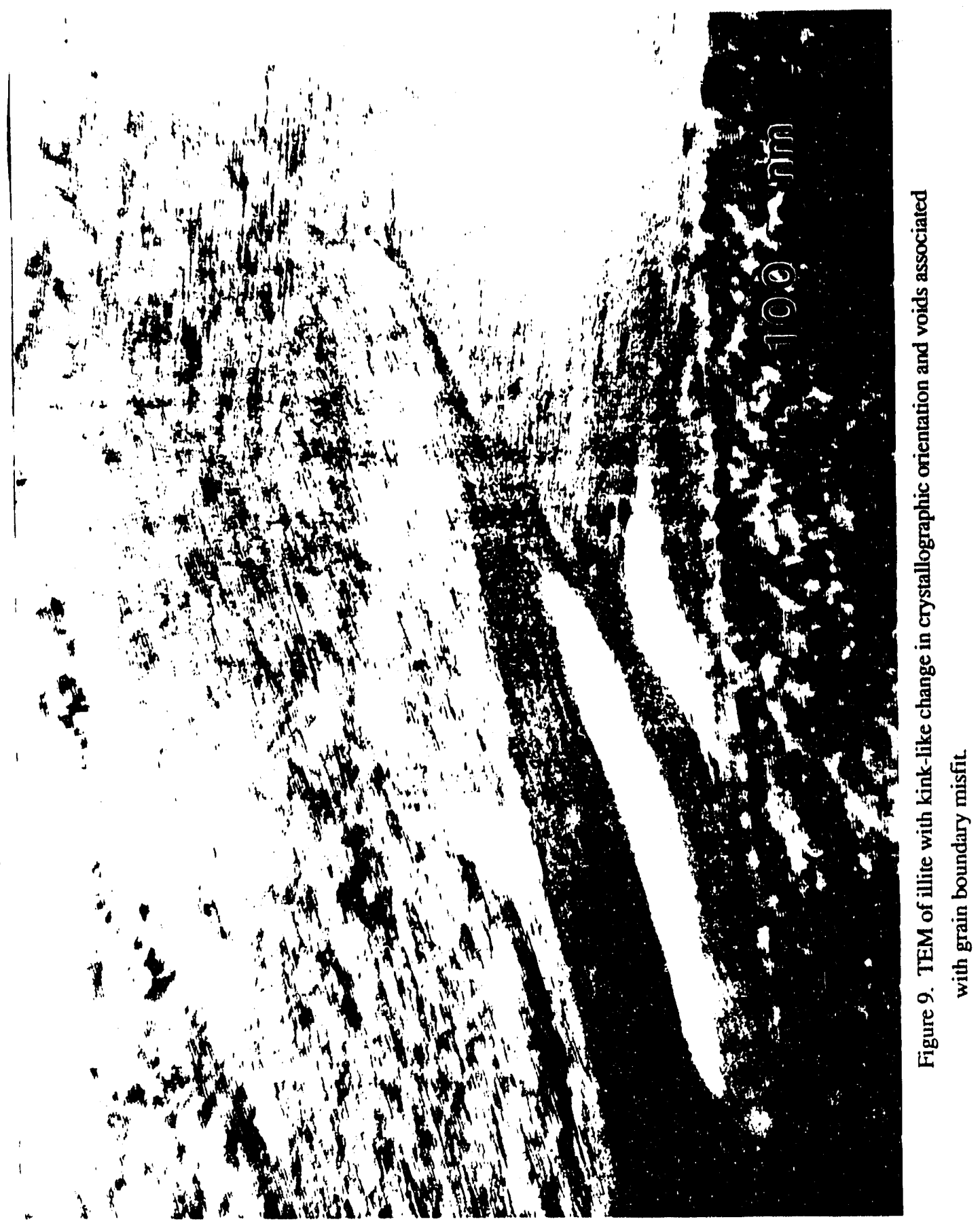




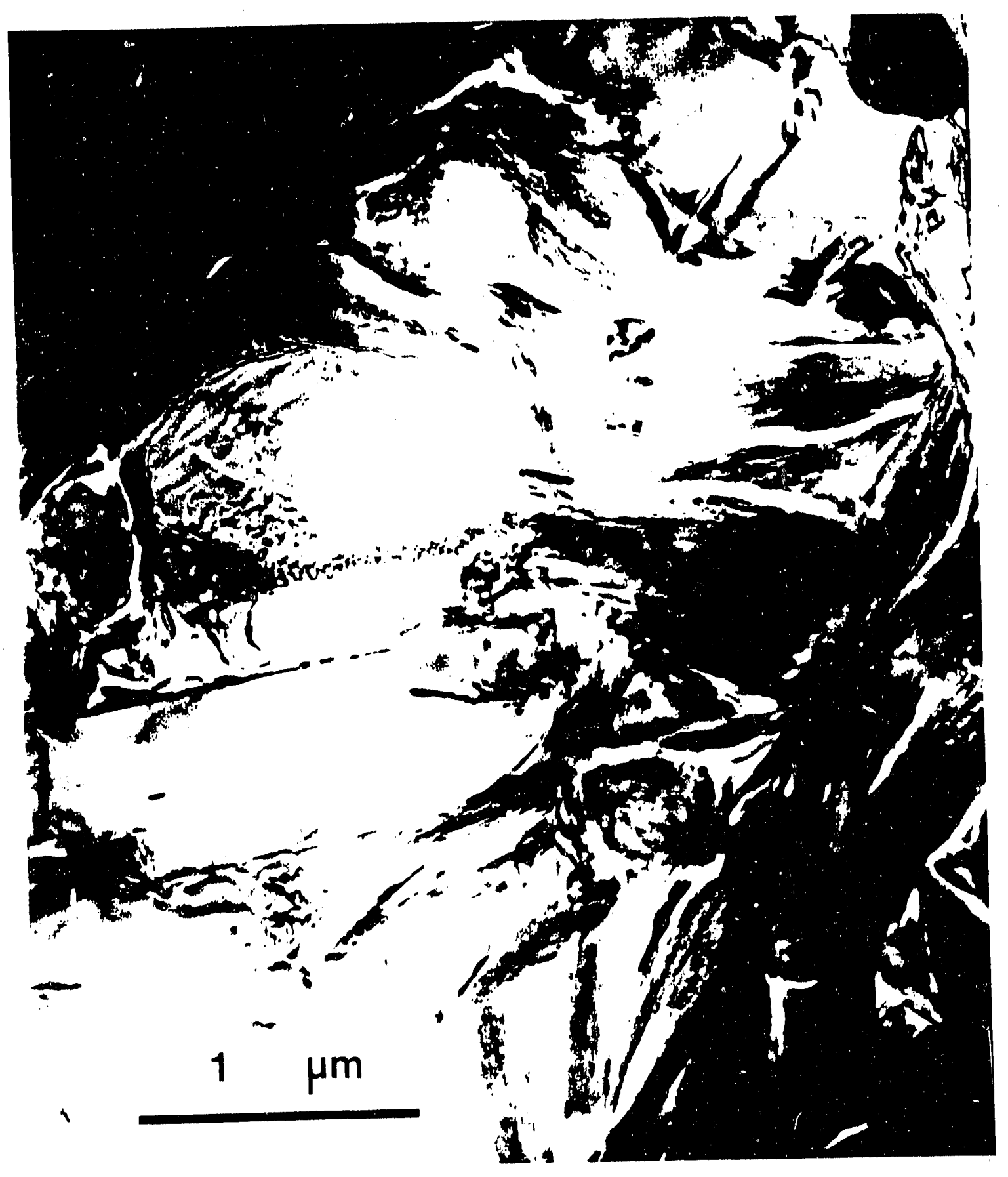

Figure 10. TEM of clays with widely varying crystallographic orientations, associated with regions of particularly high porosity. Fine detrital quartz grains are also apparent. 


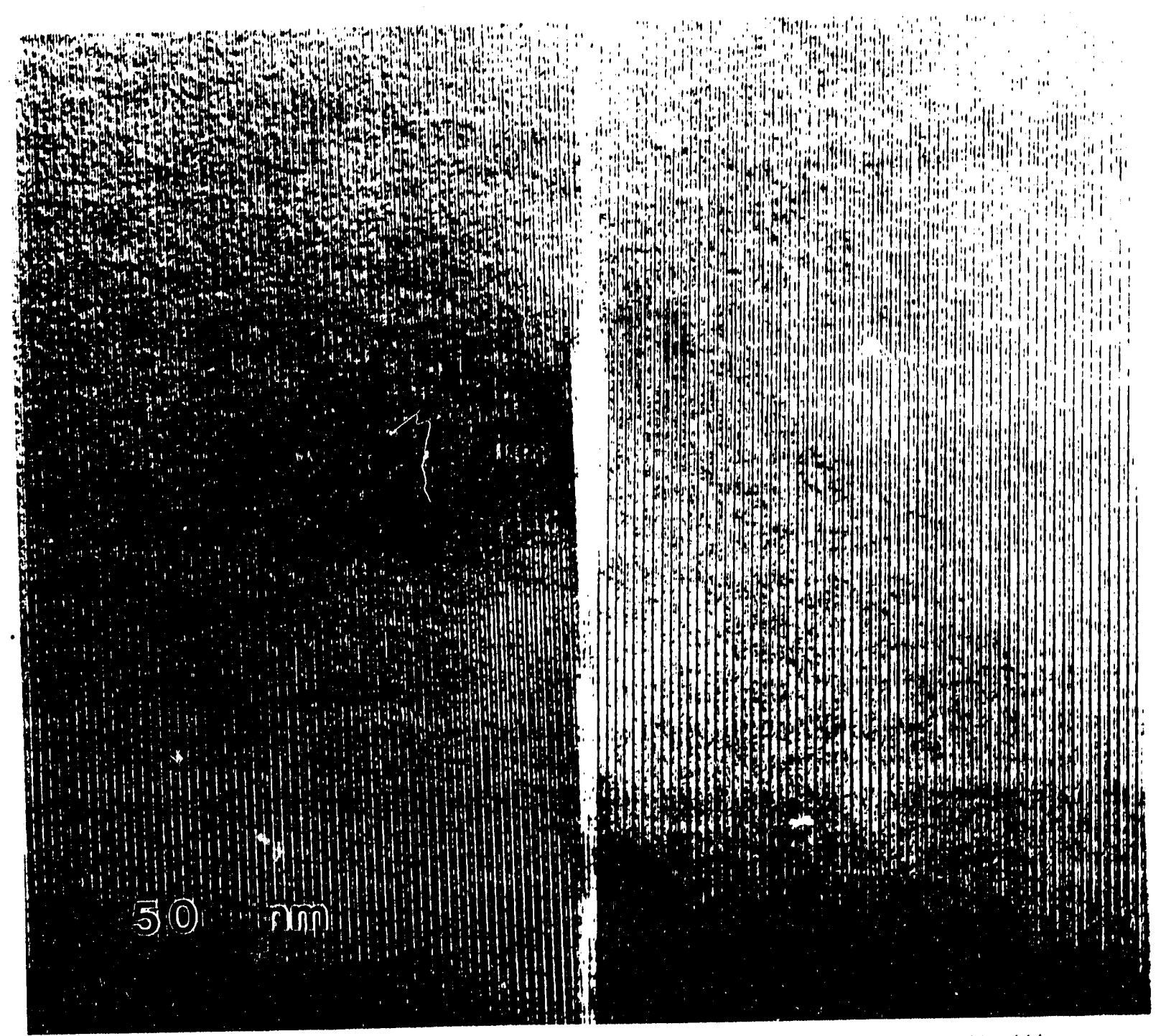

Figure 11. High resolution TEM of low-angle grain boundary (predominantly a tilt wall) within chlorite with unit cell spacing of $14.1 \AA$. 


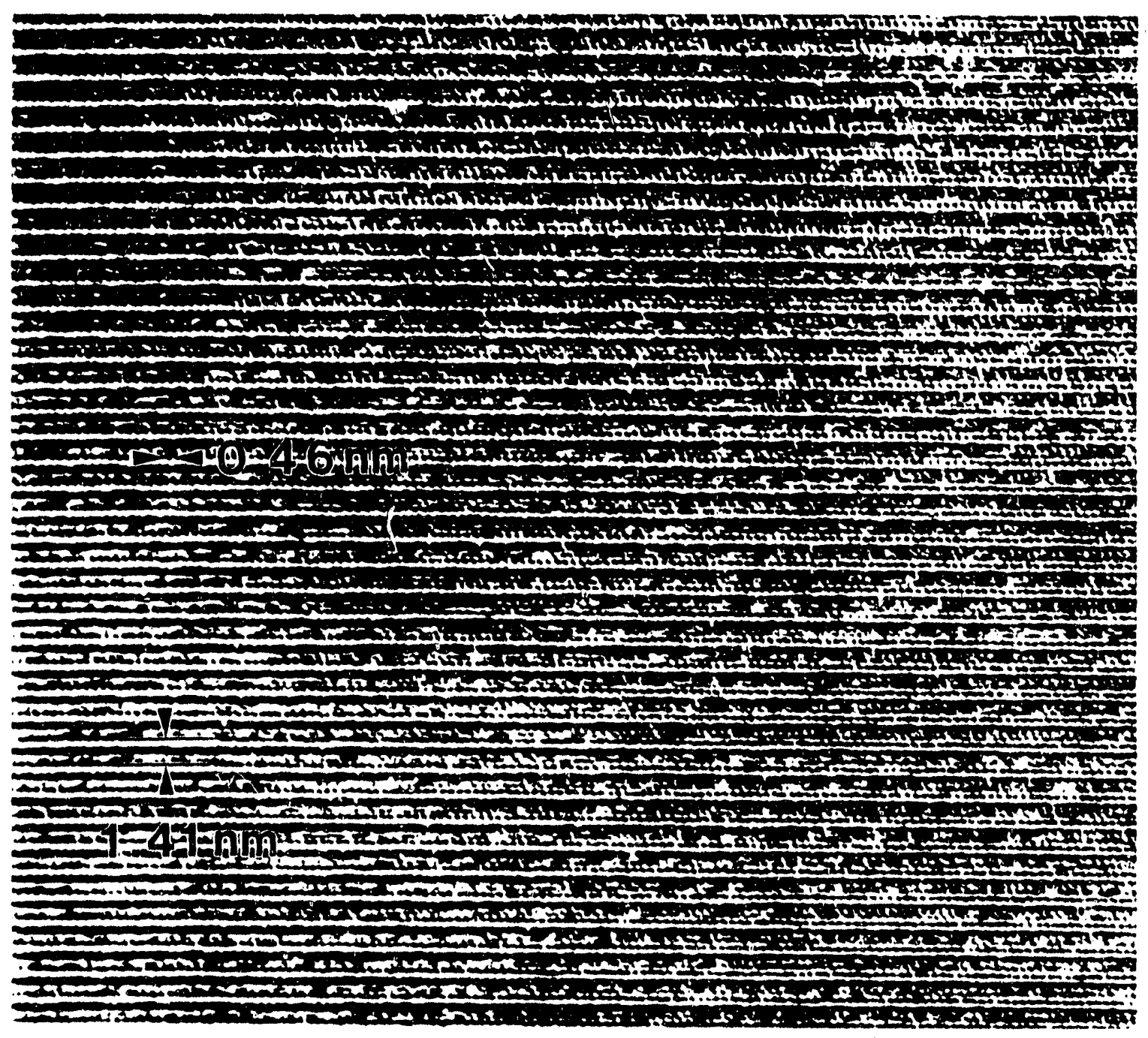

Figure 12. High resolution TEM of chlorite with basal sheets spaced $14.1 \AA$ and lattice spacing of $4.6 \AA$ within the basal plane (associated with 110 reflections). 
fractions, respectively, suggest illite/mica contents of $45 \%$ and $28 \%$. Cation exchange capacities of 0.176 and $0.297 \mathrm{rnol}^{-\mathrm{kg}^{-1}}$ for the coarse and fine clay fractions, respectively, suggest smectite/(kaolinite + smectite) ratios of $12 \%$ and $24 \%$.

IR measurements of powder samples embedded in $\mathrm{KBr}$ reveal hydroxyl and molecular water associated with several clay types, including sharp $\mathrm{OH}$-stretching bands (Figure 3, bands a and $\mathrm{b}$ ) assigned to hydroxyl in illite and kaolinite and broad bands at $3400 \mathrm{~cm}^{-1}$ and $1625 \mathrm{~cm}^{-1}$ (bands $\mathrm{c}$ and d) assigned to the $\mathrm{OH}$ stretch and $\mathrm{HOH}$ bend modes, respectively, of molecular water in the smectites. The total water content of the shale starting material $(1.8 \mathrm{wt} \%)$ was determined by measuring the weight loss of a disaggregated sample following heat treatment at $80^{\circ} \mathrm{C}$ for 24 hours.

The preferred orientation of illite grains within the starting material has been determined by $\mathrm{X}$ ray goniometry using the $(001)$ reflection. Ilite basal planes are preferentially oriented parallel to bedding as indicated by broad (001) maxima perpendicular to bedding (Figure 4), with maximum Xray intensities of $\sim 4$ times that expected for a random orientation distribution. Maxima of this order appear to be characteristic of a wide number of shales we have sampled, and are much smaller than are typically observed in higher grade slates and phyllites.

The starting material has been examined by optical microscopy, SEM, and TEM. Morphologies of the disaggregated grains in SEM (Figure 5) and TEM (Figure 6) were used to confirm the results of $\mathrm{X}$-ray diffraction for the different size fractions. TEM of intact, ion-milled samples was used to examins the intergranular textures of the starting material and high resolution lattice imaging was used to identify individual clay grains and look for interlayering of mixed clays. TEM of intact samples show complex microstructures associated with deposition and burial down to extremely small scales. Basal planes of illite (Figure 7 and 8 ) are typically wavy, similar to those observed in other shales by Ahn et al. (1983) and Lee et al. (1985). Extremely fine illite grains show complex patterns of growth with open nm-scaie voids. Polygonal voids are common (Figure 9) associated with incompatible grain shapes and changes in clay orientation. Regions of particularly high porosity (Figure 10) appear to be associated with clay grains that have nearly random crystallographic orientations in regions that locally may have escaped compaction and preserve original depositional textures of clays (Bennett et al., 1981). Direct lattice imaging using high resolution TEM has revealed basal layer spacings of $7 \AA, 10 \AA$, and $14 \AA$ (Figures 11 and 12) for individual clay grains but, thus far, we have not found intergrown mixed-layer clays.

\section{Experimental Data}

The results of triaxial, constant strain rate experiments performed on shale are assembled in Table 1. Several experiments were performed at multiples conditions, step-wise decreasing strain rate $\dot{\varepsilon}$ or increasing temperatures $T$ and the results of these experiments are listed in Tables 2 and 3 , respectively. Right circular samples were loaded parallel, perpendicular, and at $45^{\circ}$ to bedding 
without prior heat treatment or hydration. Anisotropy is displayed at all confining pressures tested (Figure 13) with the highest differential stresses measured for samples shortened parallel to bedding, with somewhat lower stresses measured perpendicular to bedding, and the lowest stresses measured at $45^{\circ}$ to bedding. Stress-strain curves typically exhibit transients in differential stress to strains of 5$6 \%$, after which stresses are relatively constant with occasional, small stress drops for samples that developed discrete shear fractures.

Deformation is Srittle at low confining pressures $\left(\mathrm{P}_{\mathrm{c}} \leq 60 \mathrm{MPa}\right)$ while transitional brittleductile behavior is observed at the higher pressures $\left(\mathrm{P}_{\mathrm{c}} \geq 100 \mathrm{MPa}\right)$, as indicated by sample barrelling accompanied by shear zone development (Table 1). Mohr envelopes for samples of all three orientations are nonlinear (Figure 14) with apparent values of internal friction $\mu$ that decrease with increasing normal stress. Samples loaded at $45^{\circ}$ to bedding exhibit the greatest curvature and the weakest pressure dependence at high pressures with $\mu \simeq 0.18$ (at $\sigma_{n}=250$ ), compared with $\mu=0.30$ for samples loaded parallel to bedding.

We have yet to make TEM observations of the deformed samples that will help identify the mechanisms of deformation. Most previous experimental studies of shale deformation have emphasized the roles of brittle mechanisms, from macroscopic fracture to microscopic cataclasis (Handin et al., 1963; Chenevert and Gatlin, 1965; McLamore and Gray, 1967; Van Eeckhout, 1976; Peng and Okubo, 1978; Chong et al., 1979; Bauer, 1980; Smith and Cheatham, 1980). More recently, evidence has been found for basal shear and kinking (Nuesch, 1989, 1991); however, shear has been assumed to occur by homogeneous slip on hydrated clay layers rather than by dislocation glide. TEM observations of deformed shale samples have not been carried out in any studies that we are aware of and we look forward to testing for the generation and motion of dislocations. Dislocation glide is common to most crystalline solids. If shear on hydrated clay surfaces can be demonstrated, it would represent a novel deformation mechanism similar to processes of friction and adhesion of molecularly thin liquid films (Homola et al., 1989). If on the other hand dislocations are generated, the dangling bonds are likely to occur within the interlayers, largely populated by molecular water.

Given that strength is less sensitive to confining pressure $P_{c}$ at high $P_{c}$, we have examined the rate and temperature dependencies of strength at $P_{C}=250 \mathrm{MPa}$ in incremental stepping tests in which individual samples were subjected to step-wise decreasing strain rates (from $10^{-4}$ to $10^{-7} \mathrm{~s}^{-1}$ ) and stepwise increasing temperatures (from $22^{\circ}$ to $130^{\circ} \mathrm{C}$ ). The results of strain rate-stepping experiments reveal a small, but systematic effect of strain rate on strength (Figures 15, 16, and 17) for all sample orientations. If an exponential glide relation of the form $\dot{\varepsilon}=A \exp \left(\alpha\left(\sigma_{1}-\sigma_{3}\right)\right\} \exp (-\mathrm{Q} / \mathrm{RT})$ is assumed, these data may be used to evaluate $\alpha$ (Figure 18). Values of $\alpha$ vary for samples of the three different orientations, from $\alpha=0.29 \mathrm{MPa}^{-1}$ for compression parallel to bedding to $\alpha=0.85 \mathrm{MPa}^{-1}$ for compression at $45^{\circ}$ to bedding. Our first temperature-stepping experiment on a sample loaded 
Table 1: Constant Strain Rate Experiments

\begin{tabular}{|c|c|c|c|c|c|c|c|c|}
\hline $\begin{array}{l}\text { Experiment } \\
\text { Number }\end{array}$ & $\begin{array}{l}\text { Confining } \\
\text { Pressure } \\
\text { (MPa) }\end{array}$ & $\varepsilon\left(s^{-1}\right)$ & $\mathrm{T}\left({ }^{\circ} \mathrm{C}\right)$ & $\begin{array}{c}\left(\sigma_{1}-\sigma_{3}\right) \text { at } \\
\text { plateau } \\
(\mathrm{MPa})\end{array}$ & $\begin{array}{c}\varepsilon \text { at } \\
\text { plateau } \\
\text { stress } \\
(\%)\end{array}$ & $\begin{array}{c}\text { Total } \\
\varepsilon \\
(\%)\end{array}$ & $\begin{array}{c}\text { Fault } \\
\text { Plane } \\
\text { Angle } \\
\left({ }^{\circ} \text { to Load }\right. \\
\text { Axis })\end{array}$ & Comments \\
\hline
\end{tabular}

\section{Load Axis Perpendicular to Bedding}

\begin{tabular}{|c|c|c|c|c|c|c|c|c|}
\hline BII VSR3 & 20 & $2.2 \times 10^{-4}$ & 22 & 78.3 & 1.7 & 2.8 & $25-30$ & Faulted \\
\hline BI1 S1 R1 & 60 & $1.0 \times 10^{-3}$ & 22 & 147.9 & 3.5 & 6.1 & \multirow{7}{*}{$\begin{array}{c}25-30 \\
40\end{array}$} & Faulted \\
\hline BI1 S2 R1 & 120 & $1.0 \times 10^{-3}$ & 22 & 191.9 & 4.5 & 12.1 & & Shear zone \\
\hline BI1 S3 R4 & 200 & $1.0 \times 10^{-3}$ & 22 & 249.2 & 7.9 & 13.9 & & Barreled \\
\hline BI1 S3 VR1 & 200 & $2.2 \times 10^{-4}$ & 22 & 203.0 & 4.8 & 6.8 & & Barreled \\
\hline BII RS1.1 D $\mathrm{D}^{\dagger}$ & 250 & $2.2 \times 10^{-4}$ & 22 & 209.4 & 5.4 & 8.1 & & $\begin{array}{l}\text { Barreled } w / \text { shear } \\
\text { zone }\end{array}$ \\
\hline $\begin{array}{l}\text { BI1 TS1.1 D } \Omega \\
\text { BI1 T1.3 D }\end{array}$ & 250 & $2.2 \times 10^{-5}$ & 22 & 219.2 & 5.9 & 9.6 & & \\
\hline \multirow[t]{2}{*}{ BI1 T1.3 D } & 250 & $2.2 \times 10^{-5}$ & 200 & 182.1 & 5.7 & & & Slight barreling \\
\hline & \multicolumn{3}{|c|}{ Load Axis } & Parallel to & Bedding & & & \\
\hline BI1 S1 R2 & 60 & $1.0 \times 10^{-3}$ & 22 & 148.6 & 1.9 & 2.9 & $25-30$ & \multirow{4}{*}{$\begin{array}{l}\text { Faulted } \\
\text { Conjugate } \\
\text { faults } \\
\text { Barreled } w / \\
\text { conjugate shear } \\
\text { zones } \\
\text { Barreled } w / \\
\text { conjugate shear } \\
\text { zone }\end{array}$} \\
\hline BI1 S2 R2 & 120 & $1.0 \times 10^{-3}$ & 22 & 202.1 & 3.6 & 5.7 & 35 & \\
\hline BI1 S3 R2 & 200 & $1.0 \times 10^{-3}$ & 22 & 264.3 & 6.3 & 12.6 & 37 & \\
\hline BIl RS2.1 D $\mathrm{D}^{\dagger}$ & 250 & $2.2 \times 10^{-4}$ & 22 & 218.5 & 5.2 & 10.0 & & \\
\hline
\end{tabular}

Load Axts at $45^{\circ}$ to Bedding

\begin{tabular}{|c|c|c|c|c|c|c|c|c|}
\hline BI1 S1 R3 & 60 & $1.0 \times 10^{-3}$ & 22 & 113.5 & 2.2 & 3.2 & $40-45$ & Faulted \\
\hline BI1 S2 R3 & 120 & $1.0 \times 10^{-3}$ & 22 & 167.3 & 3.3 & 9.9 & $35-40$ & $\begin{array}{l}\text { Slight barreling } \\
\text { w/conjugate } \\
\text { shear zone }\end{array}$ \\
\hline BI1 S3 R3 & 200 & $1.0 \times 10^{-3}$ & 22 & 200.5 & 12.7 & 12.8 & 35 & $\begin{array}{l}\text { Barreled w/shear } \\
\text { zone }\end{array}$ \\
\hline BI1 RS3.2 $\mathrm{D}^{\dagger}$ & 250 & $2.2 \times 10^{-4}$ & 22 & 167.0 & 5.1 & 8.0 & & $\begin{array}{l}\text { Barreled w/shear } \\
\text { zone }\end{array}$ \\
\hline BII RS3.3 $\mathrm{D}^{\dagger}$ & 250 & $2.2 \times 10^{-4}$ & 22 & 198.3 & 5.5 & 8.2 & & $\begin{array}{l}\text { Barreled w/shear } \\
\text { zone }\end{array}$ \\
\hline BI1 RS3.4 $\mathrm{D}^{\dagger}$ & 250 & $2.2 \times 10^{-4}$ & 22 & 188.2 & 6.5 & 9.5 & & $\begin{array}{l}\text { Barreled w/shear } \\
\text { zone }\end{array}$ \\
\hline
\end{tabular}

\footnotetext{
$\dagger \quad$ Rate Stepping-Experiment

$\Omega \quad$ Temperature-Stepping Experiment
} 


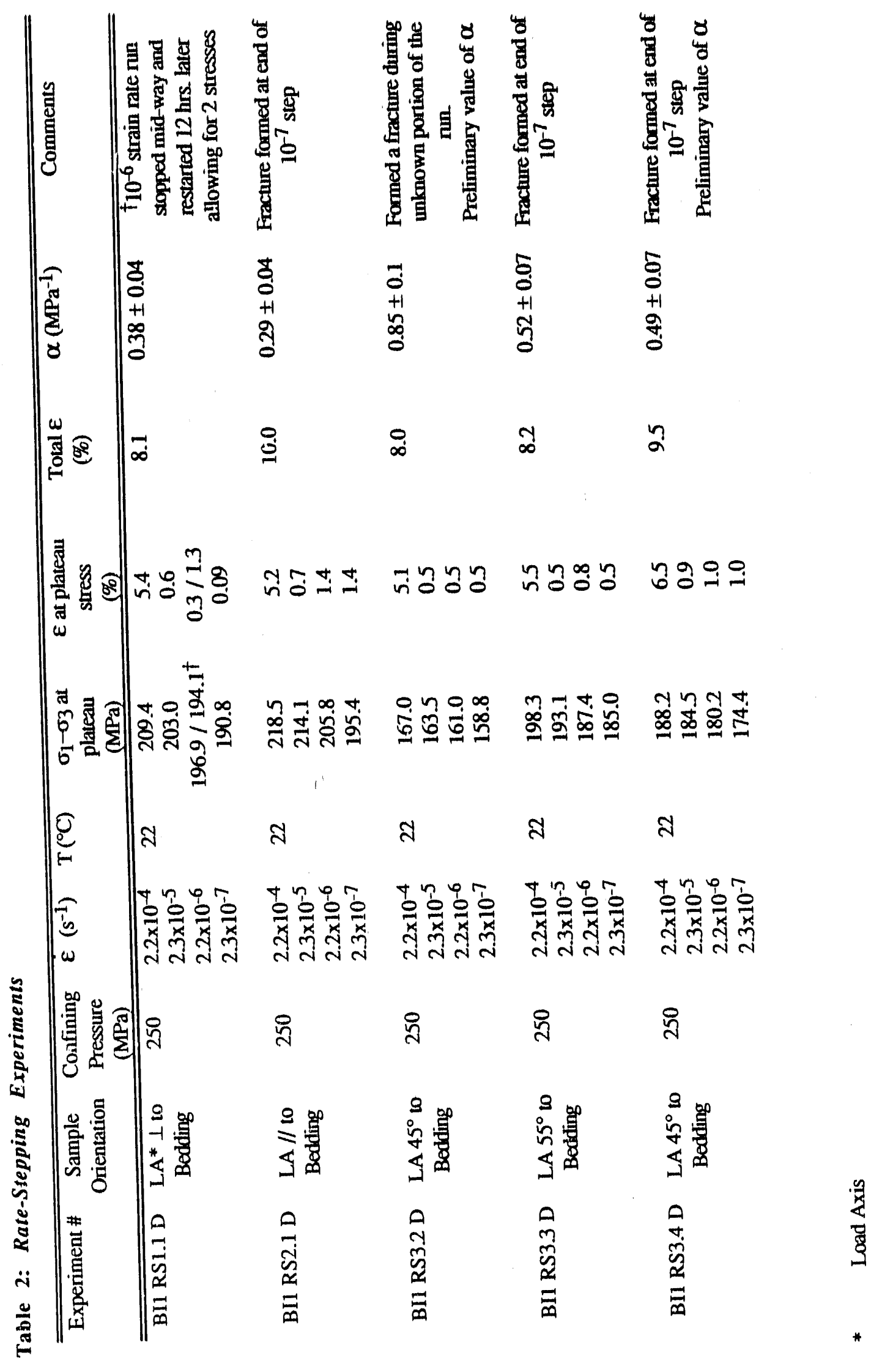




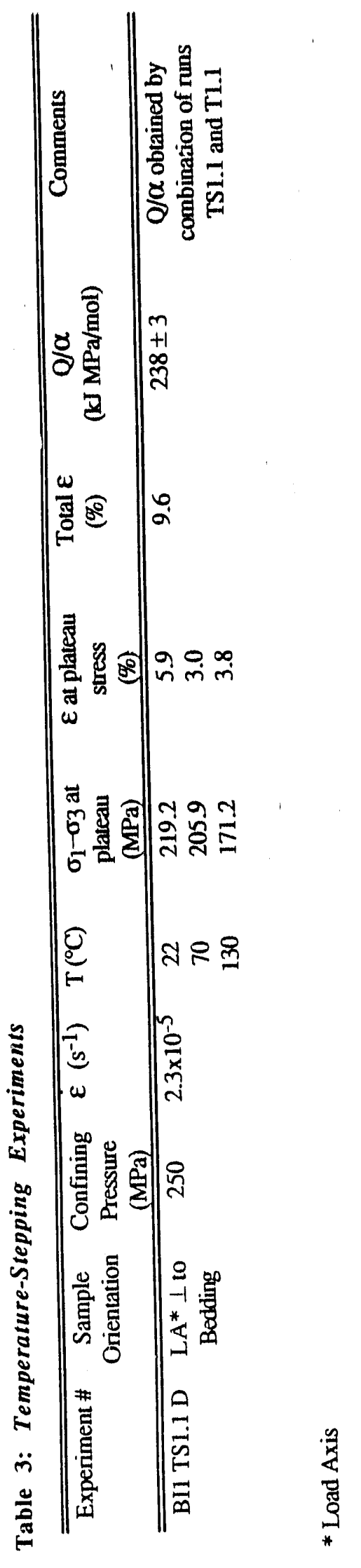



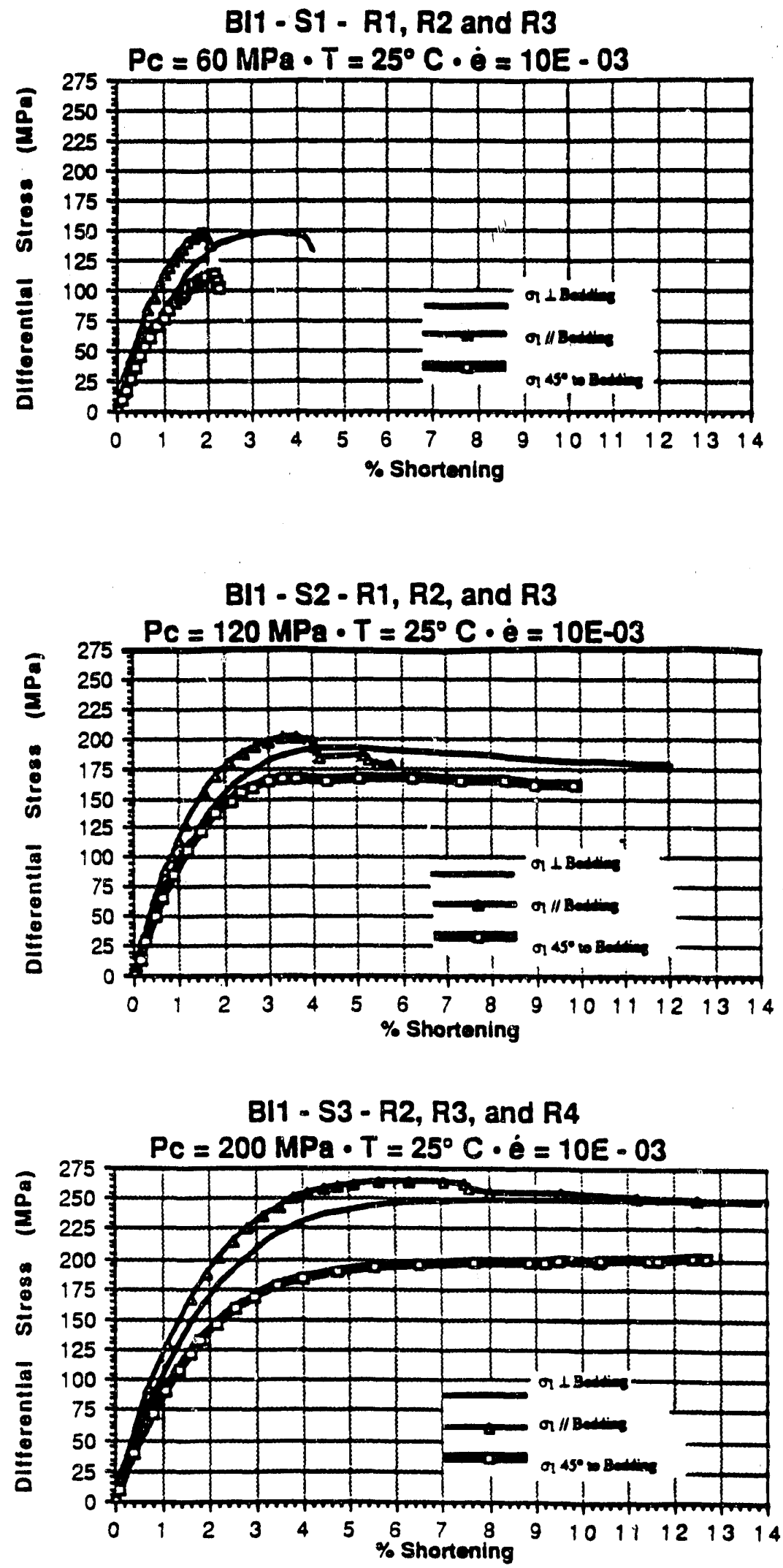

Figure 13. Differential stress-strain data for shale samples cored parallel, perpendicular, and at $45^{\circ}$ to bedding and deformed at constant strain rate at three different confining pressures. 

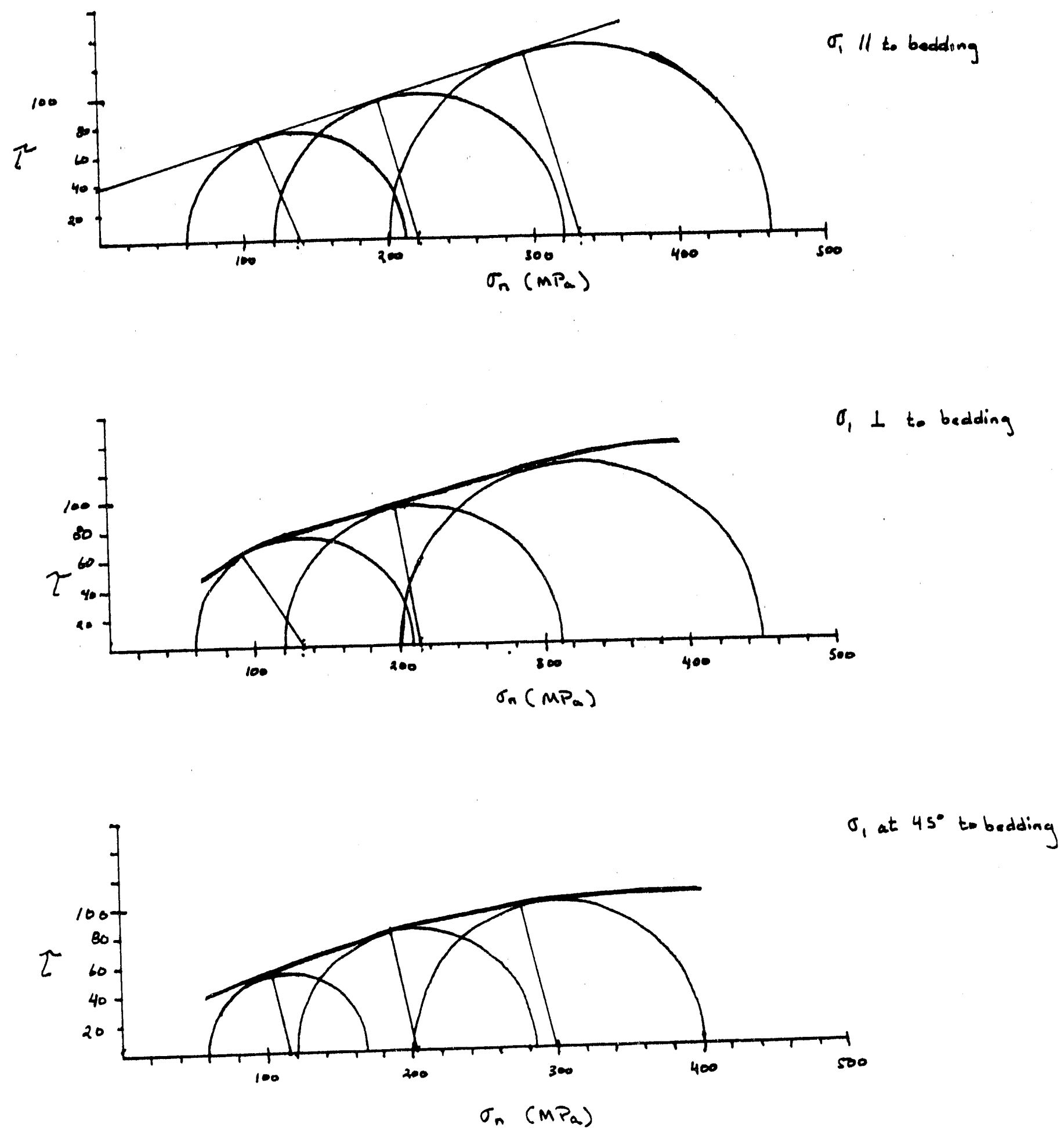

Figure 14. Mohr diagrams using results shown in Figure 13, show nonlinear yield envelopes defined at a constant strain rate. 


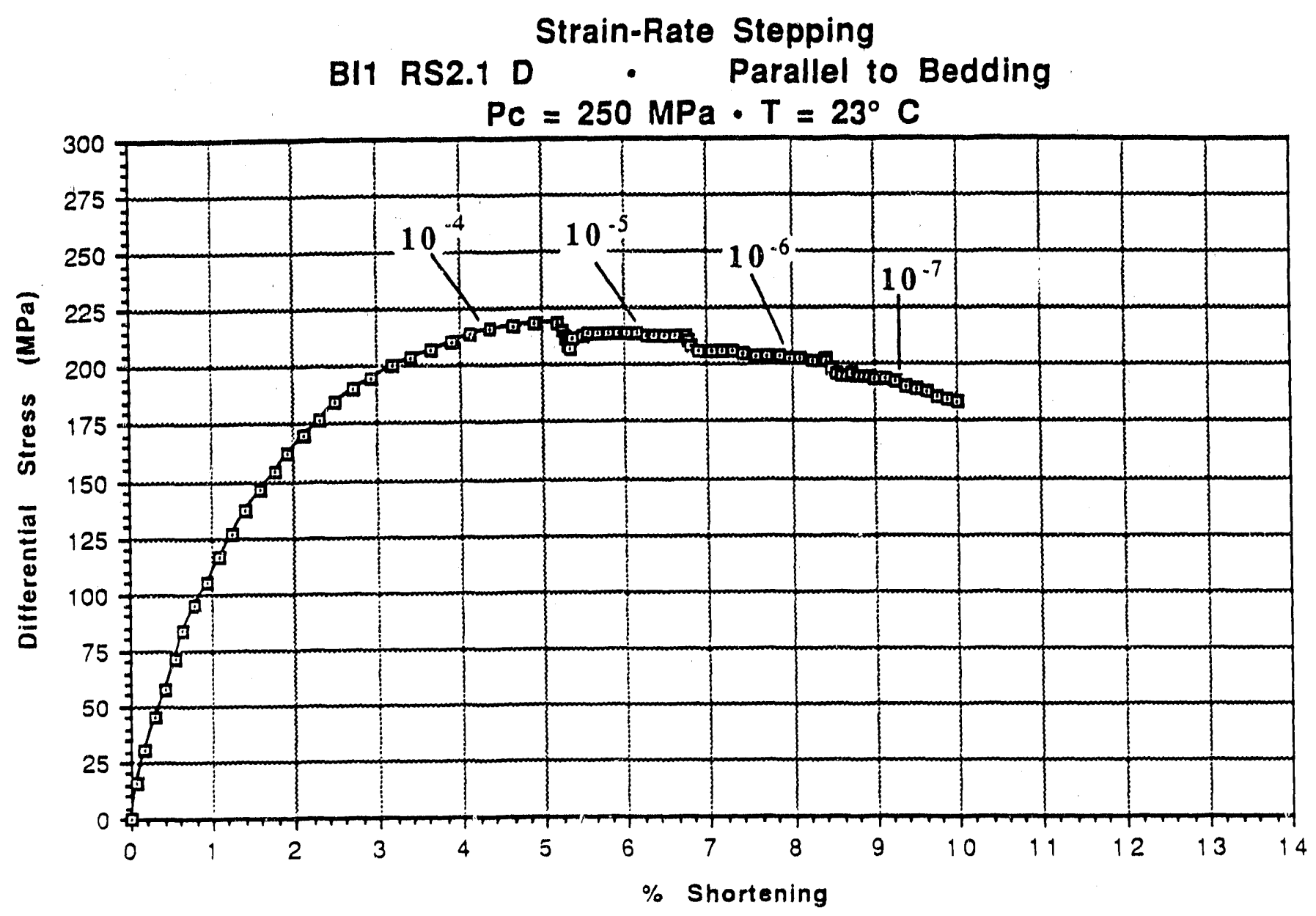

Figure 15. Strain rate-stepping experiment performed on sample loaded parallel to bedding. 


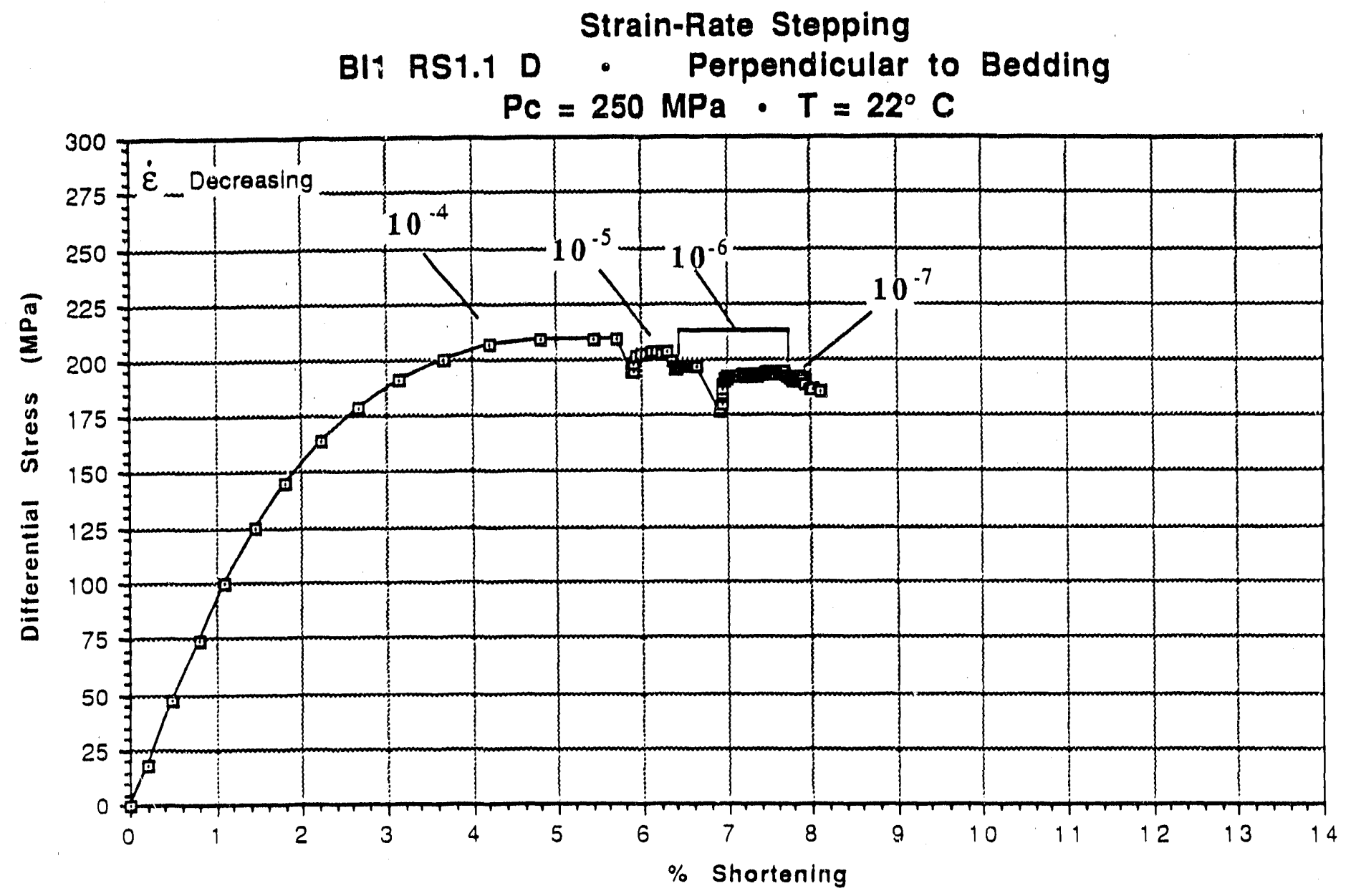

Figure 16. Strain rate-stepping experiment on sample loaded perpendicular to bedding. 


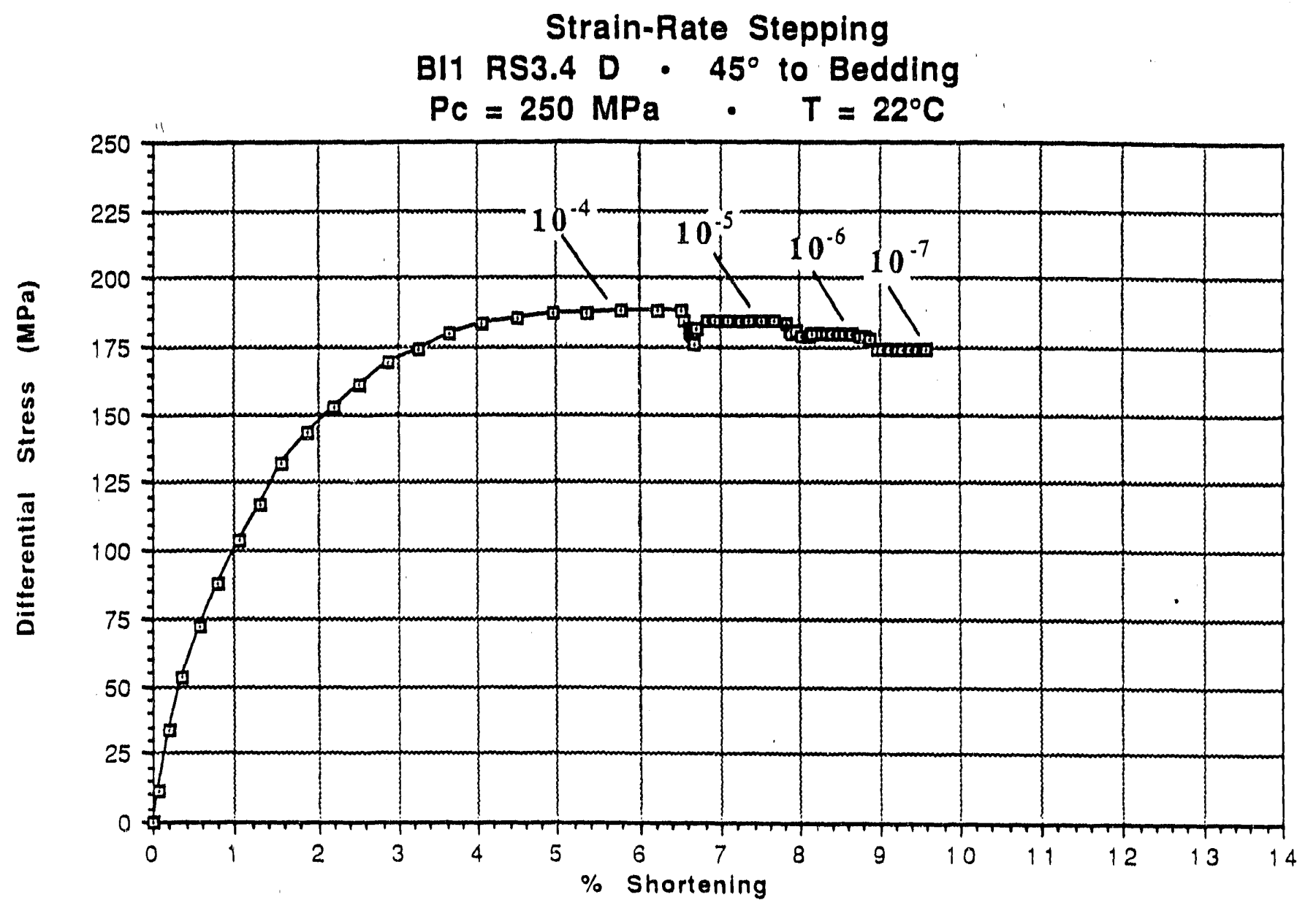

Figure 17. Strain rate-stepping experiment on sample loaded at $45^{\circ}$ to bedding. 


\section{Differential Stress -vs- $\ln (\dot{\varepsilon})$}

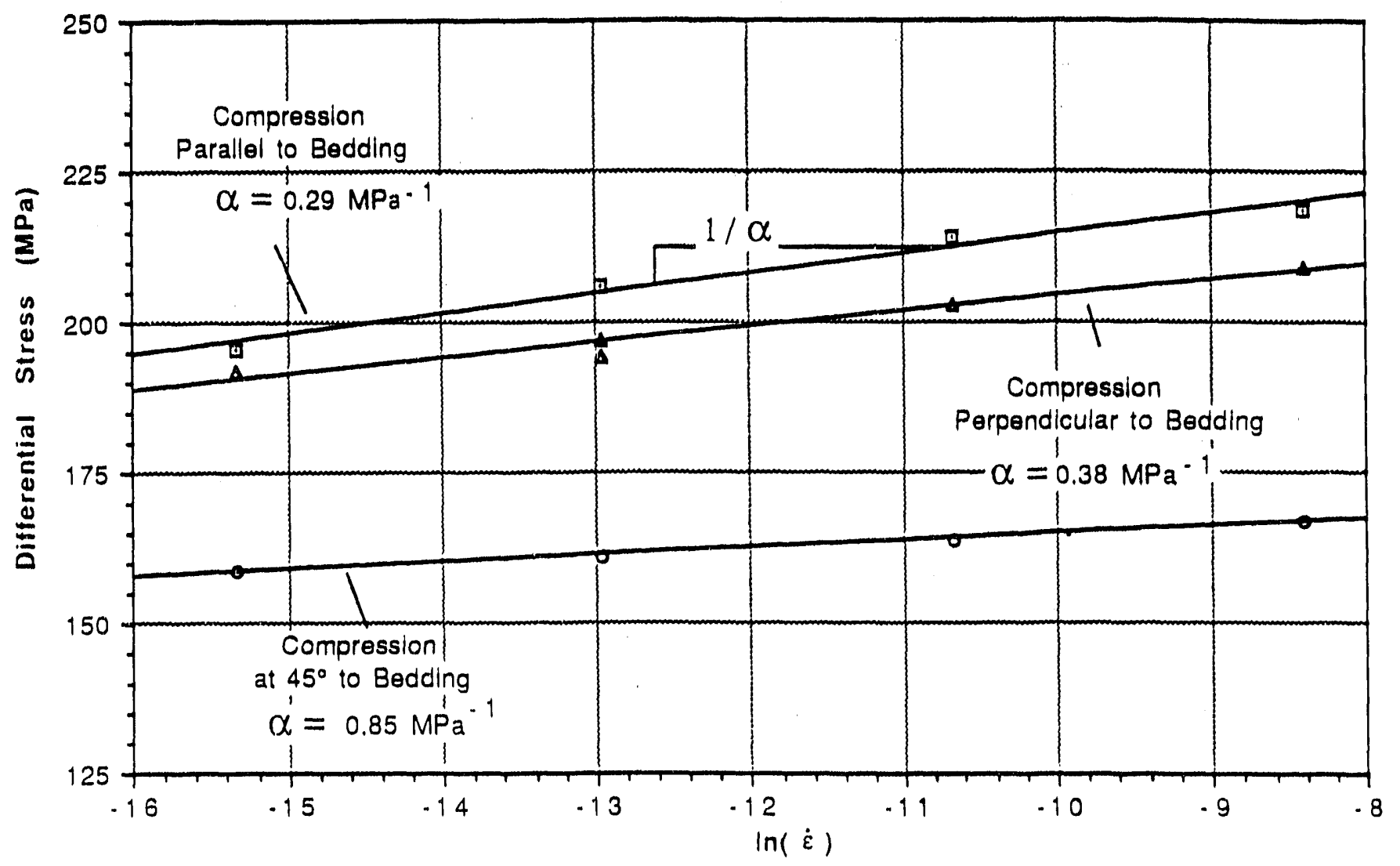

Figure 18. Results of strain rate-stepping experiments, plotted as differential stress $\left(\sigma_{1}-\sigma_{3}\right)$ versus $\ln$ $\dot{\varepsilon}$. 


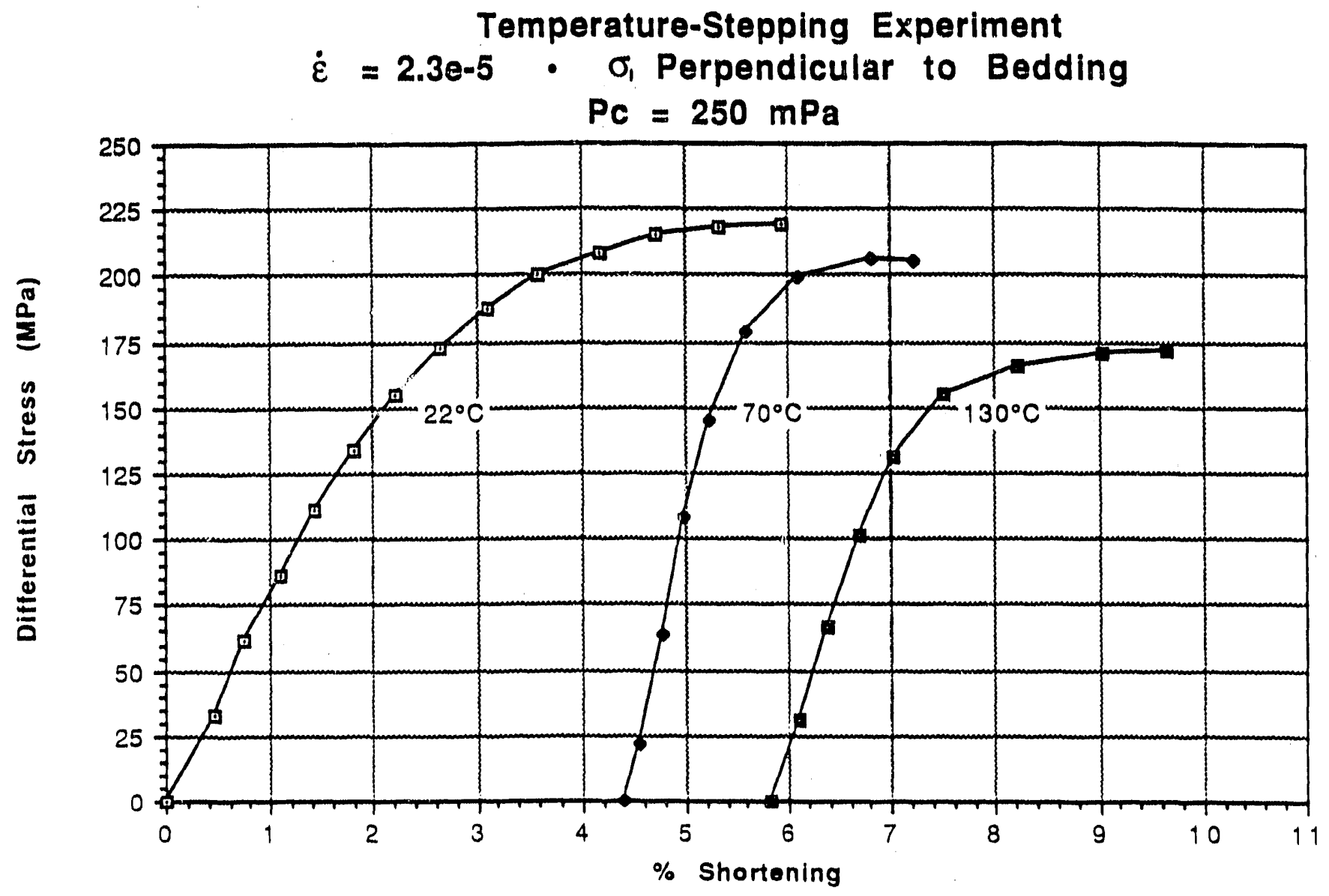

Figure 19. Temperature-stepping experiment performed on sample load perpendicular to bedding. 
Differential Stress -vs- $1 / T$

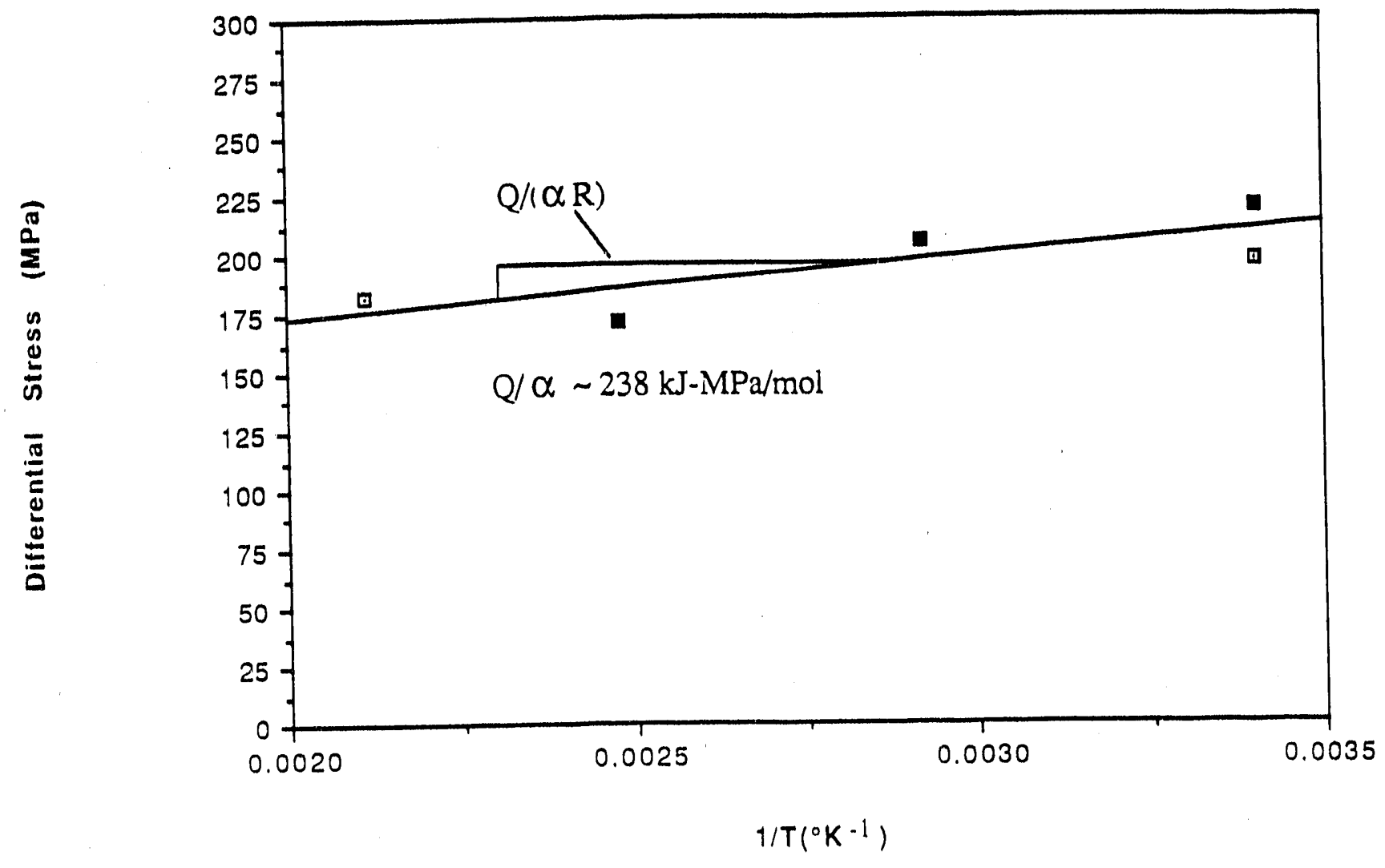

Figure 20. Results of temperature-stepping experiment (solid squares) and individual tests at $22^{\circ}$ and $200^{\circ} \mathrm{C}$ (open squares), plotted as differential stress $\left(\sigma_{1}-\sigma_{3}\right)$ versus $1 / \mathrm{T}$. 
perpendicular to bedding likewise shows that differential stress depends upon temperature (Figure 19). Combined with results of individual tests at $22^{\circ}$ and $200^{\circ} \mathrm{C}$, we can estimate the value of $\mathrm{Q} / \alpha \cong$ $238 \mathrm{~kJ}-\mathrm{MPa}^{-\mathrm{mol}^{-1}}$ (Figure 20). Although dislocation glide has yet to be demonstrated, the values of $\alpha$ (typically from 0.29 to $\left.0.52 \mathrm{MPa}^{-1}\right)$ and $\mathrm{Q}(\sim 90 \mathrm{~kJ} / \mathrm{mol}$ ) for shale are remarkably similar to those ( $\alpha$ $=0.15 \mathrm{MPa}^{-1}$ and $\mathrm{Q}=89 \mathrm{~kJ} / \mathrm{mol}$ ) for dislocation glide and kinking in biotite schist (Shea and Kronenberg, 1992).

\section{Mechanical Modeling of the Growth of Salt Structures}

The development of a finite difference code to model the growth of large scale salt structures has proceeded by defining an Eularian (fixed) mesh of cells. Within each of these cells the fluid is characterized by average values of velocity, pressure, volume fraction of each fluid, density and viscosity. The changes of these quantities with time can be computed with the aid of finite difference approximations to the full Navier-Stokes equations.

\section{Differential Equations}

In two dimensions the partial differential equations to be solved are the Navier-Stokes equations

$$
\begin{aligned}
& u, t+u u_{, x}+v v, y=-p, x+v i s x+g_{x} \\
& v, t+u v, x+v v, y=-p, y+v i s y+g_{y}
\end{aligned}
$$

where $(u, v)$ are the $(x, y)$ velocity components and $p$ is the pressure. Fluid density has been normalized to unity (or equivalently, $\mathrm{p}$ can be viewed as the ratio of pressure to constant density). The components (visx, visy) represent viscous stresses,

$$
\begin{aligned}
& \text { visx }=v(u, x x+v, y y) \\
& v i s y=v(v, x x+v, y y)
\end{aligned}
$$

where $v$ is a constant coefficient of kinematic viscosity.

Fluid pressure is to be determined from the condition of incompressibility,

$$
\mathrm{u}, \mathrm{x}+\mathrm{v}, \mathrm{y}=0
$$


which states that the divergence of the velocity must vanish. Forming the divergence of equation (1) and using equation (3) results in a Poisson equation for pressure, which is used for pressure correction calculations.

The steady-state solution is desired, and this can be achieved either by advancing the equations set (1) - (3) through a sequence of time steps or by dropping the time term completely from the equations and using a pure iterative approach (Jung, 1988); we have chosen the earlier one.

\section{Mesh layout and variables placement}

Figure 21a shows a planar region covered by a mesh of equal-sized rectangular cells of width $\delta x$ and height $\delta y$. Marked cells with a '.' are "fictitious" cells and are used only to impose boundary conditions. The flow region is covered by the interior, unmarked cells. Horizontal velocity $u$, vertical velocity $v$, pressure $\mathrm{p}$, and volume fraction $\mathrm{f} 1$, are to be thought of as located at the cell position shown in Figure 21b. This so-called staggered mesh was introduced by Harlow and Welch (1965). This mesh arrangement has advantages for incompressible flow calculations, as it leads to highly localized finite difference approximations (Hirt, 1982). In the staggered mesh, the velocity and pressure are not defined in the same mesh points. As seen in Figure 22 the velocity is defined at the half mesh points.

\section{Finite-Difference Equations}

Discretization of equations (1) - (3) has been done using a central finite difference approximation of the derivatives. We have tested the explicit, implicit and mixed formulation of the discretized equations in order to evaluate which one is more convenient in terms of speed of convergence, stability and accuracy. The explicit formulation gave accurate results, however the time step needed was impractically small for the time scale of the problem we are solving (millions of years). The implicit formulation that allows one to take large time steps, although unconditionally stable, showed lack of the desired accuracy. The mixed explicit-implicit formulation is the one which has given more acceptable results, and matches Chandrasakhar's analytical solutions within less than $2 \%$ of error.

\section{Pressure correction}

In the present study we use the primitive variables $(u, v, p)$ in the solution of the incompressible Navier-Stokes equations. This approach has an advantage over the stream function approach, in that it can be extended to three dimensional flows (Chorin, 1967). However, the 


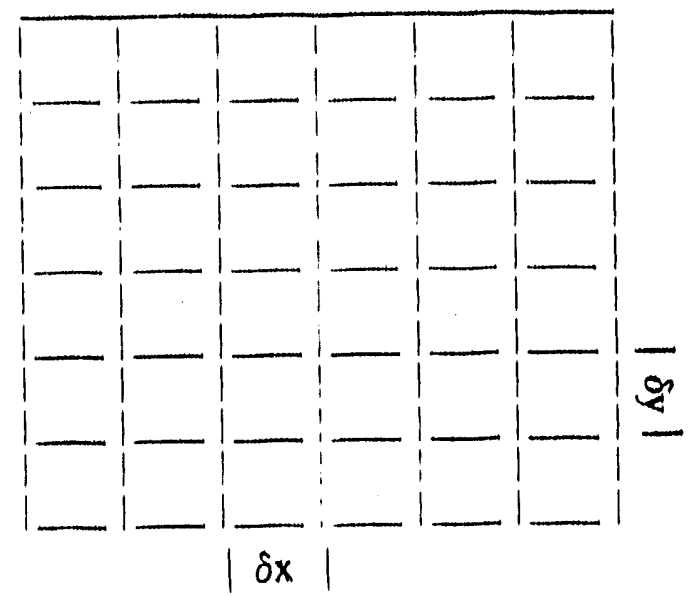

(a)

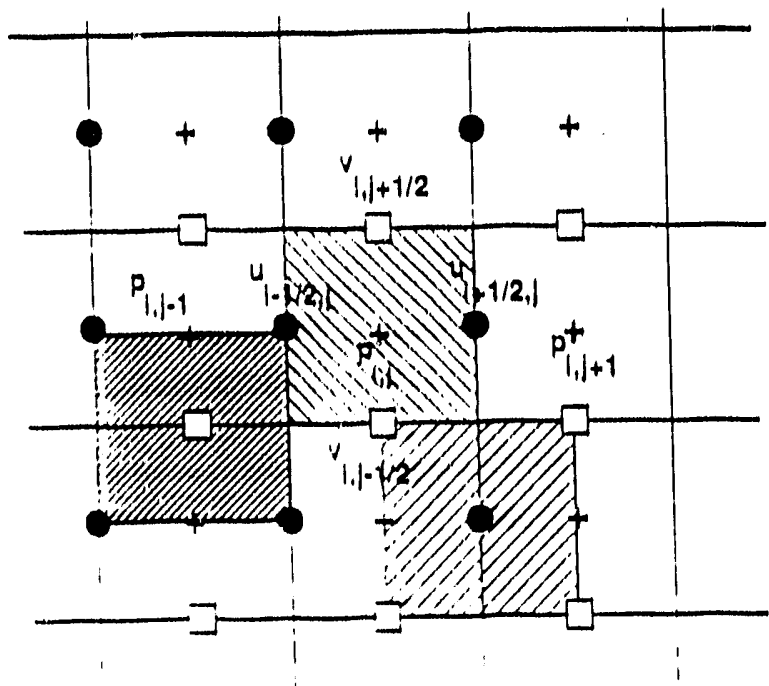

anurol cell for mass conservauon

control cell for $x \cdot$ momentum conscrvation

centrol cell ior y-momenum conservation

(b)

Figure 21. Mesh layout and variable placement. (a) Cells with a dot $(\bullet)$ indicate "fictitious" cells to impose boundary conditions. (b) Staggered, two-dimensional finite difference mesh for centrally discretized pressure correction methods (from Hirsch, 1990). 
One of the most important steps prior to the application of a numerical model is its validation. In the present study analytical solutions are available for this purpose. However, the solutions available are valid only for a linear viscosity model under isothermal conditions. Those solutions are also valid only for the early stages of the evolution of the perturbing anomaly, i.e. when the ratio of the amplitude/wavelength is less than 0.1 . Those analytical solutions provide information regarding the dominant wavelength, for which a perturbing anomaly will growth the fastest, giving the expected spacing between anomalies (salt domes).

We have coded Chandrasekhar's analytical solutions in Fortran 77 for a flexible interface between two infinite half-spaces. Growth rates obtained using the numerical model compare well with Chandrasekhar's analytical solutions within $2 \%$ error for low viscosity cases $\left(10^{-5}-10^{2}\right.$ $\mathrm{Pa} . \mathrm{s}$ ) and within 25-30\% for high viscosity cases (> 1016 Pa. s).

When using a kinematic viscosity value of $10^{-8}$ in SI units, the numerical growth factor obtained using the computer program is $2.666 \mathrm{sec}^{-1}$ and the analytical value is $2.698 \mathrm{sec}^{-1}$, a differunce of only $1.16 \%$ between numerical and analytical results. Table 4 presents the parameters used in the model of figure 22. The slope of the curve of figure 22 represents the growth factor.

To evaluate a geological example, Ramberg's analytical solutions for a two layer model were coded in Fortran 77. In the model the bottom boundary is considered to be fixed. The upper boundary is fixed in the vertical direction, but is free to move in the horizontal direction. This model allows finite thicknesses of salt and sediment layers. Table 5 shows the parameters used in the geological case. Figures $23 \mathrm{a}$ and $23 \mathrm{~b}$ show the plots of natural $\log$ of amplitude and amplitude, respectively, vs geological time in millions of years. The viscosities for sediments and salt are $10^{19}$ $\mathrm{Pa}-\mathrm{s}$ and $1017 \mathrm{~Pa}$-s. The growth rates obtained using the computer model at this stage are about 30 \%faster than those predicted from Ramberg's analytical solutions. Refinement of the pressurevelocity linked algorithm is necessary in order to better account for the coupling between the pressure correction and the viscous term. Viscous terms are the dominant ones in the evolution of salt structures. Figure 24 shows a sequence of snapshots of the actual evolution of the simulated salt structure as a function of the geologic time in million years. The shapes reveal the evolution of the salt structures and may be compared with geological structures interpreted from seismic data.

Constant strain rate long-duration experiments have resulted in the formulation of a new power law creep that is probably more appropriate to natural strain rates than previously reported constitutive relationships. For relatively high stress, high strain rate data $\varepsilon \alpha \sigma^{5.3}$ dominates, whereas for low stress, low strain rate data, $\varepsilon \alpha \sigma^{3.4}$. Flow rates predicted by the $\varepsilon \alpha \sigma^{3.4}$ relation are higher by two orders of magnitude than are those predicted by $\varepsilon \alpha \sigma^{5.3}$ and we may be able to use the numerical model to distinguish which of these laws matches better the rates at which salt structures develop. 
TABLE 4

Data for Model of Figure 22

(SI units)

$\begin{array}{ll}\text { Amplitude of disturbance } & 0.10 \mathrm{E}-02 \\ \text { Wavelength } & 0.160000 \\ \text { x- dimension } & 0.160000 \\ \text { y- dimension } & 1.280000 \\ \text { Density of fluid 1 } & 1000.000 \\ \text { Density of fluid 2 } & 1100.000 \\ \text { Viscosity of fludd 1 } & 1000.000 \\ \text { Viscosity of fluid 2 } & 1100.000 \\ \text { Thickness of layer 1 } & 0.640000 \\ \text { Thickness of layer 2 } & 0.640000 \\ \text { Maximun time evolution } & 10.00000 \\ \text { Number of steps } & 1500.000\end{array}$

TABLE 5

Data for Model of Figure 23 and 24

(SI units)

$\begin{array}{lr}\text { Amplitude of disturbance } & 6.2 \mathrm{E}+14 \\ \text { Wavelength } & 1.3 \mathrm{E}+04 \\ \text { x- dimension } & 1.3 \mathrm{E}+04 \\ \text { y- dimension } & 5.0 \mathrm{E}+03 \\ \text { Density of fluid 1 } & 1000.000 \\ \text { Density of fluid 2 } & 1100.000 \\ \text { Viscosity of fluid 1 } & 3.0 \mathrm{E}+17 \\ \text { Viscosity of fluid 2 } & 3.0 \mathrm{E}+19 \\ \text { Thickness of layer 1 } & 2.5 \mathrm{E}+03 \\ \text { Thickness of layer 2 } & 2.5 \mathrm{E}+03 \\ \text { Maximum time evolution } & 6.2 \mathrm{E}+14 \\ \text { Number of steps } & 1000.000\end{array}$




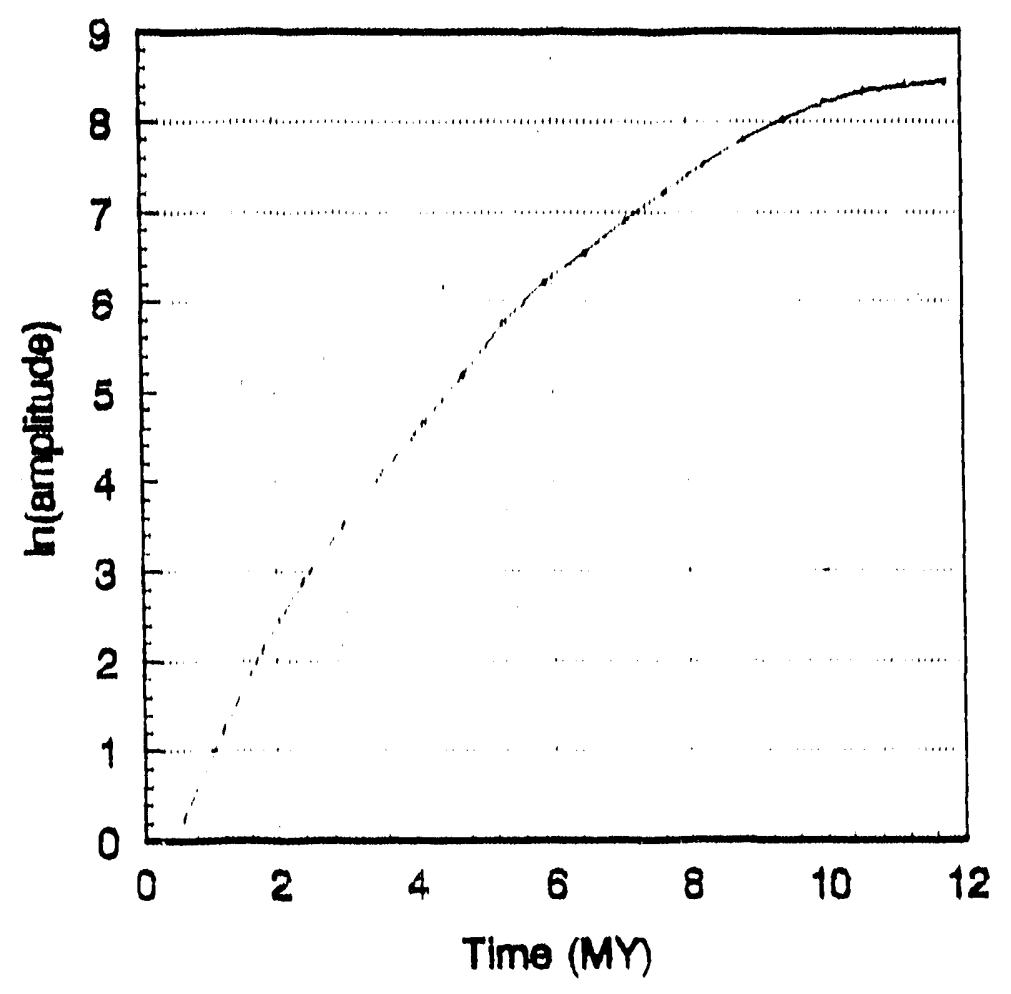

(a)

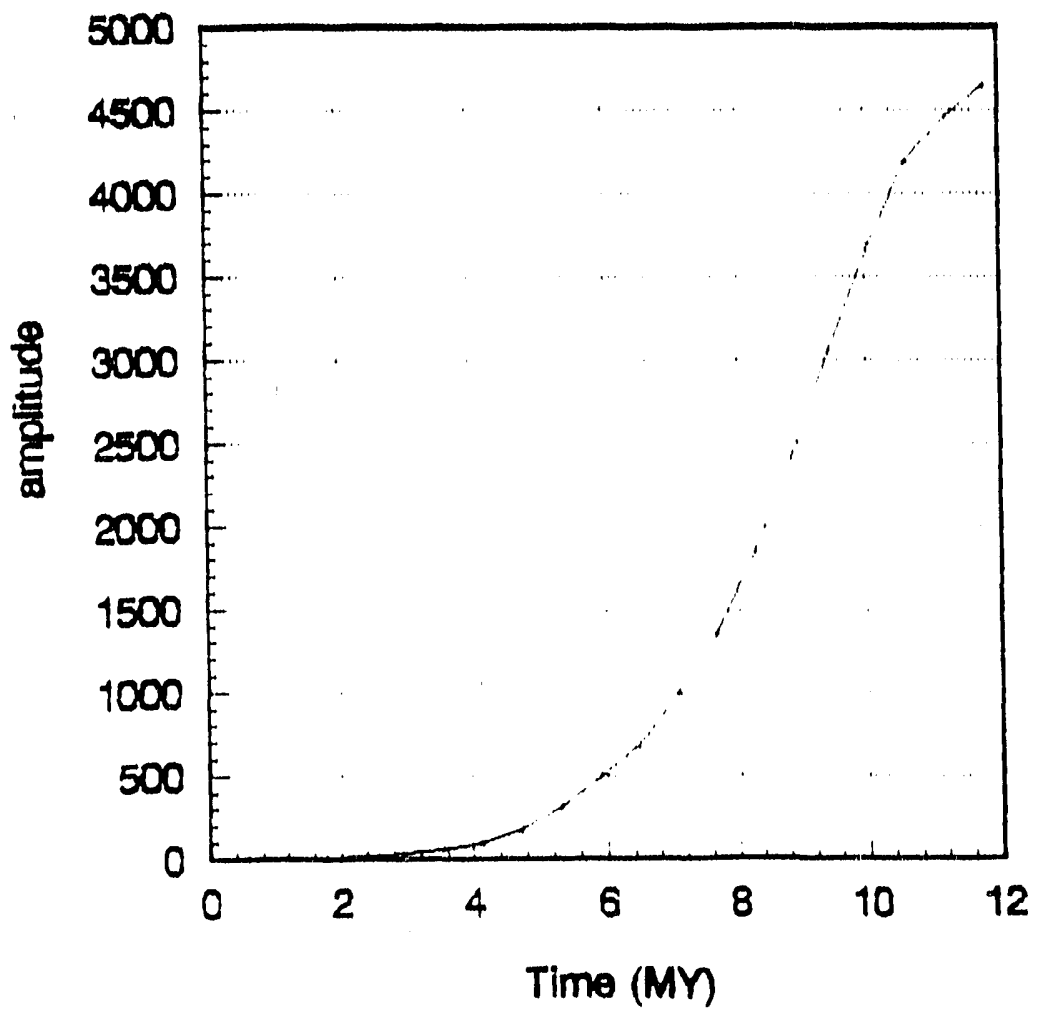

(b)

Figure 23. Evolution of a simulated salt structure with parameters of Table 5. (a) Natural log vs. time (million years), (b) amplitude (meters) vs. time in million years. 


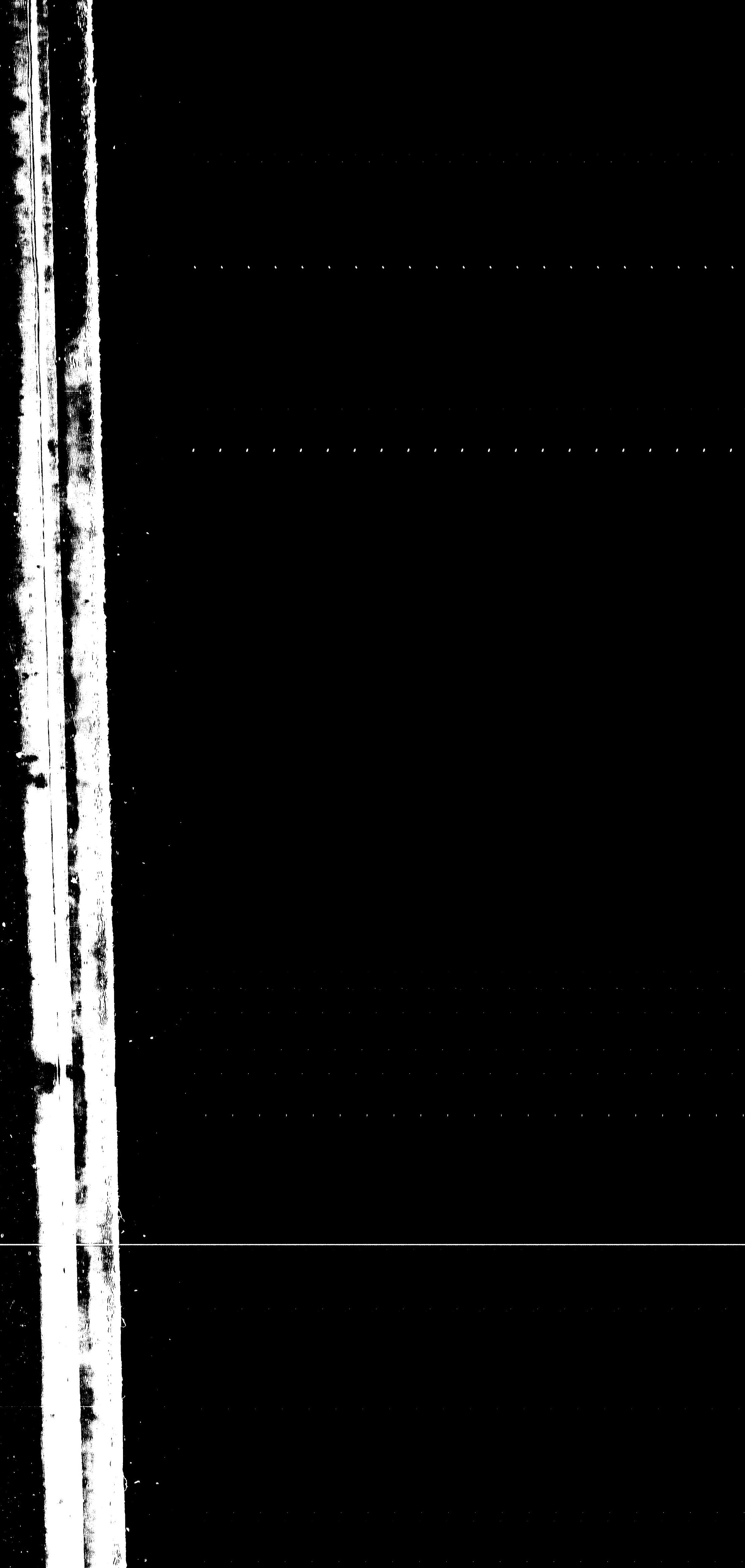




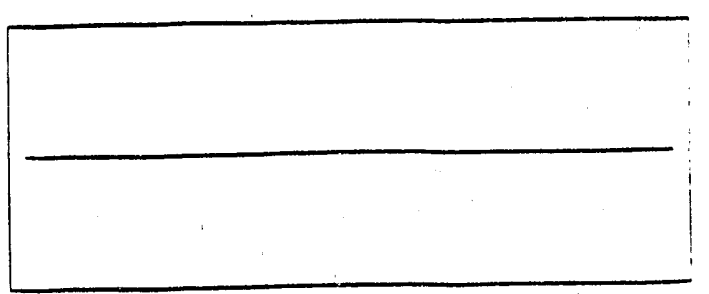

$t=0 \quad M Y$

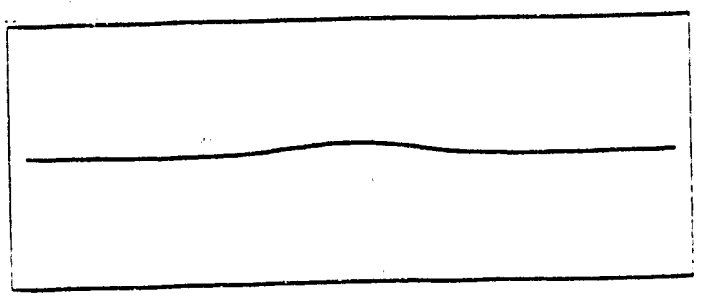

$t=5.5 \mathrm{MY}$
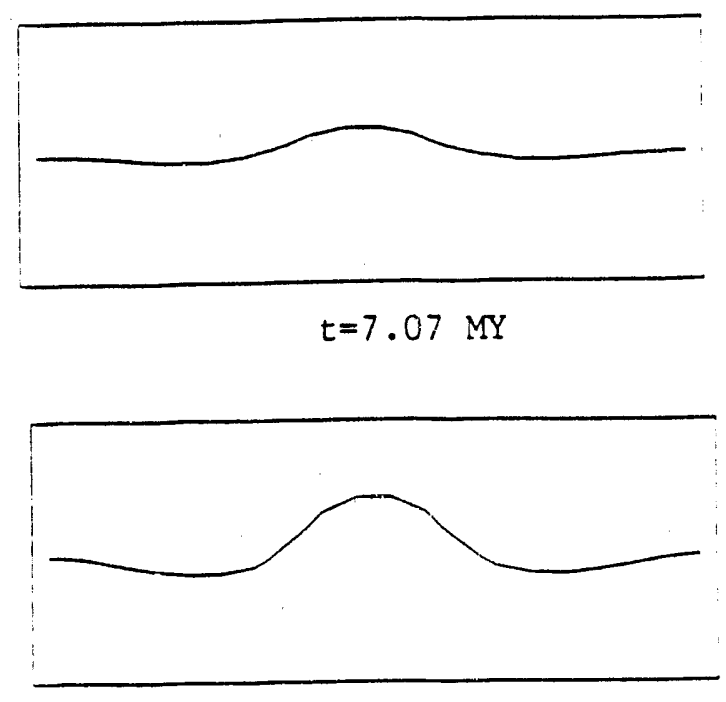

$t=8.65 \mathrm{MY}$

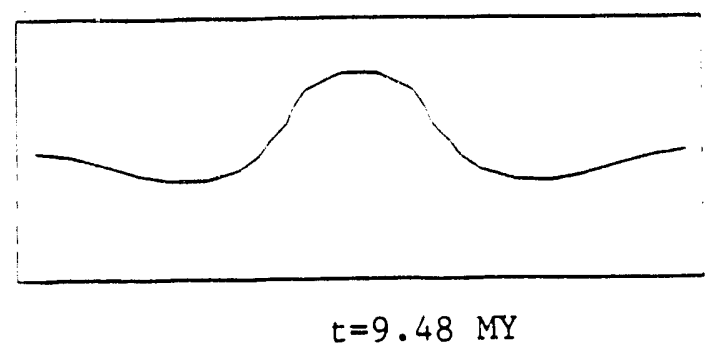

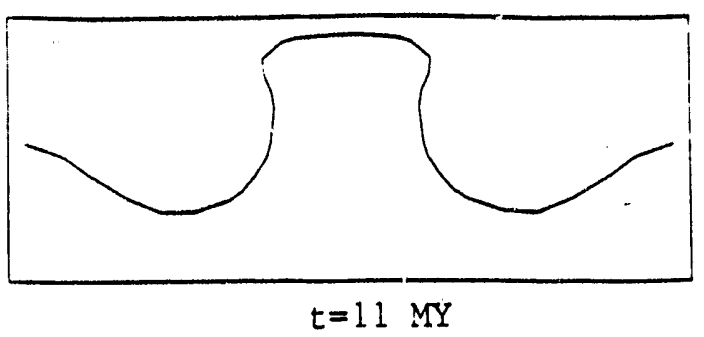
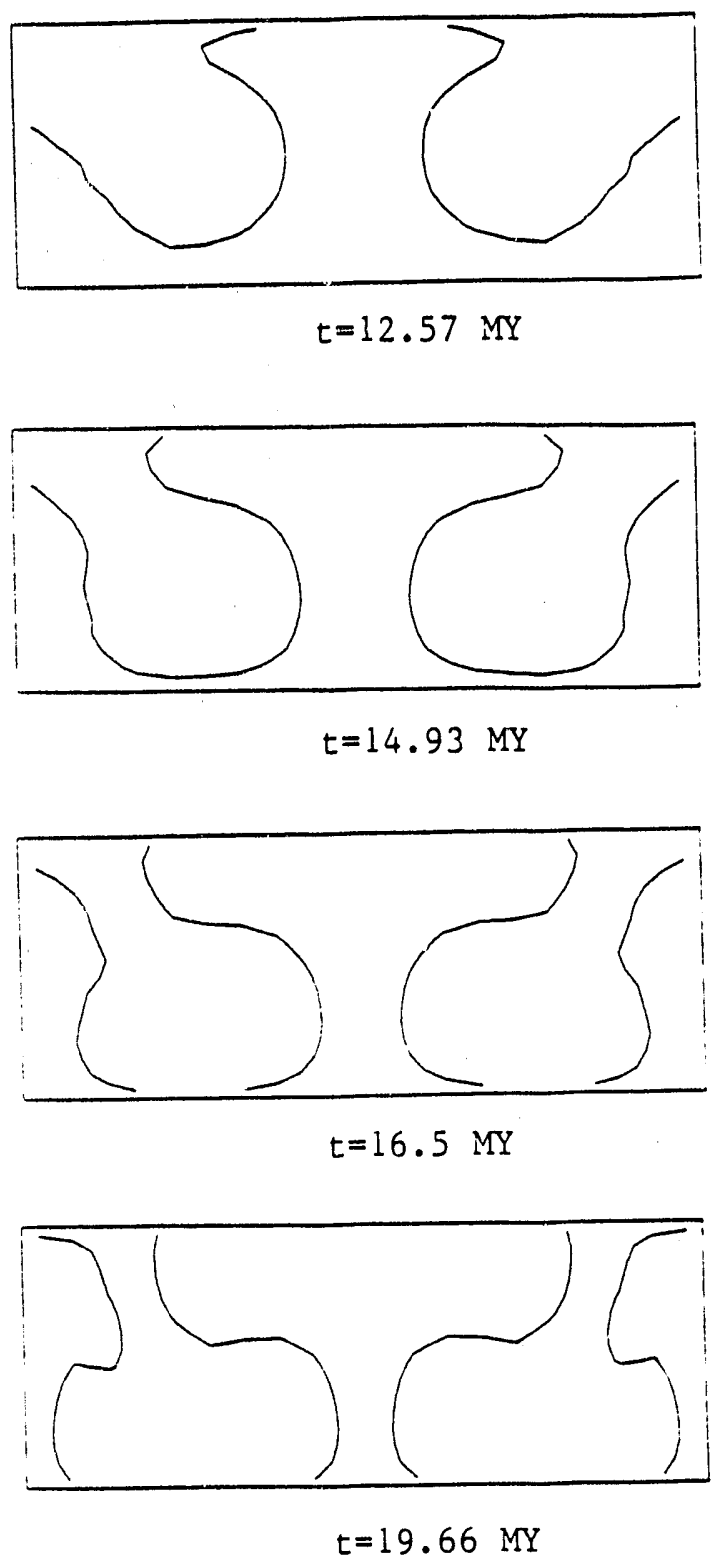

Figure 24. Evolution and shape of simulated salt structure using parameters of Table 5. 


\section{CONTINUED RESEARCH}

We are well on the way to determining the mechanical behavior of an illite-rich shale of known mineralogy and fabric for a fixed concentration of water in clay interlayers and we plan to continue our work to refine our determinations of the $\mathrm{P}, \mathrm{T}$, and $\dot{\varepsilon}$ effects on strength. However, there is still much work to be done to identify the mechanisms of deformation over the range of conditions we have examined, and to extend our study to mechanical response for varying water contents. We will soon begin TEM of the deformed samples and will look for dislocations, kink bands, microcracks, and voids that open in concert with kink band formation, as were observed in biotite schist. Changes in the populations and dimensions of pores due to deformation may have important implications for the sealing properties of shales by affecting their capillary pressures. We also plan to examine any effects of varied concentrations of clay interlayer water. Given that swelling pressures may be related to the number of water layers within clays (Madsen et al., 1976 referenced by Nuesch, 1991), the amount of water that can be accommodated within clays as layered water may be expected to vary confining pressure (Figure 25). At water contents and/or confining pressures below this relationship, all water may be accommodated within clay interlayers. At water contents and/or confining pressures that exceed this relationship, water is expected to occur as free water within pores. We plan to decrease and increase the water contents of shale samples by heat treatment in a low temperature oven and hydration in a controlled humidity chamber, respectively, prior to deformation and determine whether or not the number of water layers within clays influence their strength. The molecular water contents of samples, originally $1.8 \mathrm{wt} \%$, can readily be reduced by heat treatment, and increased by longer term exposure of samples in a controlled humidity chamber at $60^{\circ} \mathrm{C}$ and $97 \%$ relative humidity (Figure 26). Water contents of $4-5 \mathrm{wt} \%$ were achieved after $\sim 200$ hours for samples with the original $1.8 \mathrm{wt} \% \mathrm{H}_{2} \mathrm{O}$ as well as samples that had previously been dried by heat treatment. We will monitor the water contents in clay interlayers with IR absorption measurements of powder clay samples. We also plan experiments on samples with multiple water layers at pressures that exceed their stability conditions and will test for weakening associated with the generation of a pore pressure. Nuesch (1991) has examined weakening associated with the generation of fluids with increasing temperat re and we plan to take this approach by varying pressure. Determinations of swelling pressures for our shale starting material are key measurements for this approach and we plan experiments on samples in different orientations using methods described by Madsen and Müller-Von Moos (1985). Ultimately, we need to deform samples over long durations at low strain rates while monitoring pore pressure and look for transients that may be associated with spatially varying effective pressure. We also have a large collection of shales of 


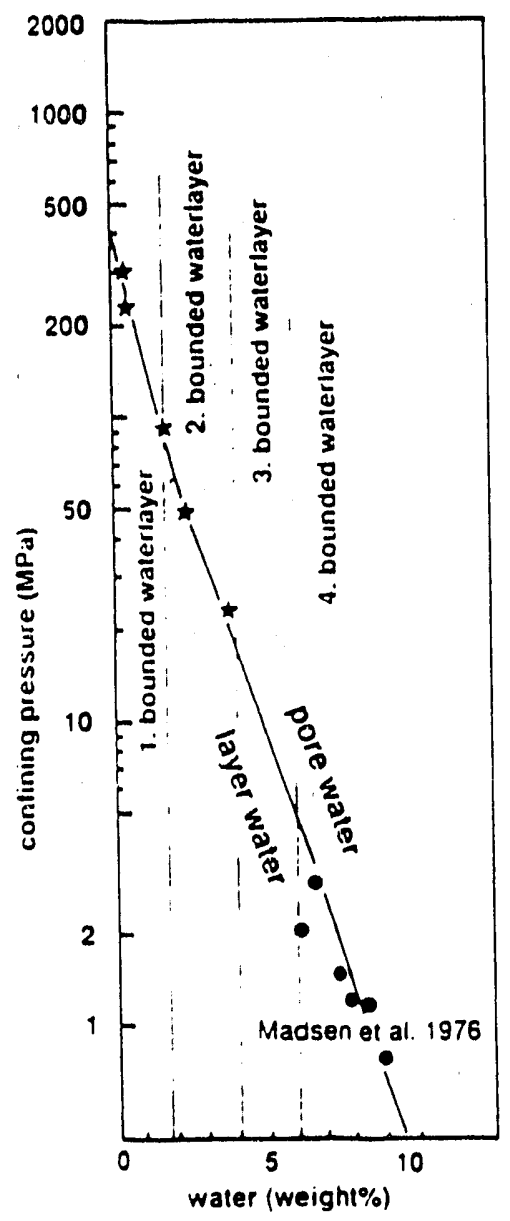

Figure 25. Stability fields of clays with multiple layers of water within their interlayers and clays in the presence of free pore water, plotting confining pressure versus water content for a clay mineral surface of $140 \mathrm{~m}^{2} \mathrm{~g}^{-1}$ (from Madsen et al., 1976 referenced by Nuesch, 1991). 


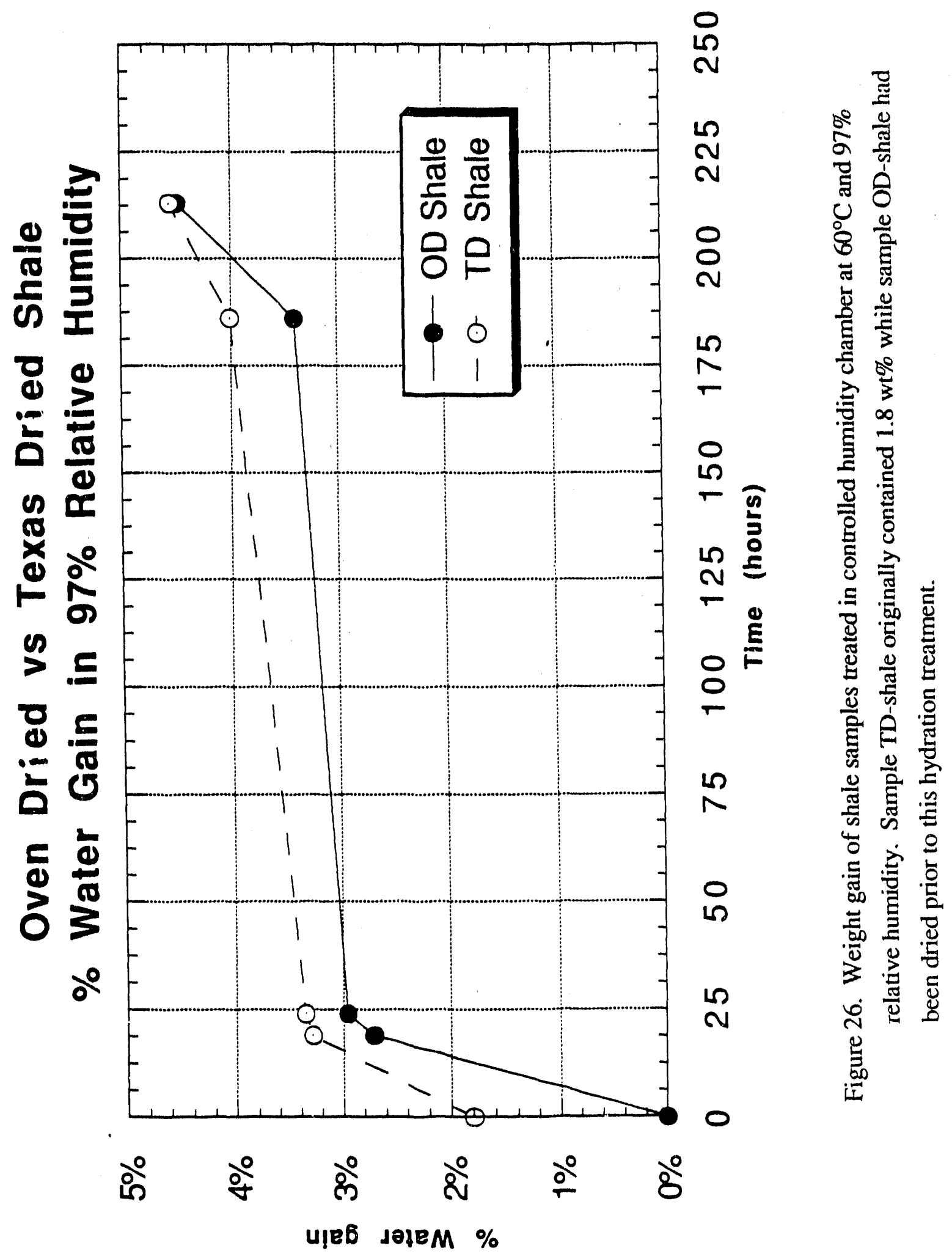


varied mineralogy and texture to examine. These starting materials are currently in storage in a large controlled humidity chamber set at $15^{\circ} \mathrm{C}$ and $70 \%$ relative humidity.

In our numerical modeling studies, we plan to refine our finite difference algorithm in order to match numerical growth rates with analytical growth rates for geological cases. Our experience shows that the coupling between viscous terms and pressure correction should be refined. We plan to accomplish this objective soon.

The next step is to implement nonlinear rheological models for salt and shale viscosities. Specifically for salt, these models include (1) power-law creep (Carter and Hansen, 1983; Carter et al., 1990), (2) steady-state fluid assisted creep law (Spiers et al., 1990), and for shale (3) a preliminary nonlinear law under isothermal conditions. The temperature dependence of the material rheology can be implemented by knowing the geothermal gradient as a function of the geologic time. However, the temperature calculation could alternatively be done by solving the heat conduction equation using finite difference approximations.

Salt structures from the Gulf of Mexico will be selected to apply the numerical model using different constitutive equations for salt rheology. By comparing the evolution of salt structures using different constitutive relations, we expect to gain an understanding of their applicability. 


\section{REFERENCES}

Ahn, J. H., J. H. Lee, and D. R. Peacor, Mineralogical and textural transitions in phyllosilicates during burial diagenesis of Gulf Coast shales, Geol. Soc. Amer. Abstr. with Prog., 15, 512, 1983.

Andrews, M.J., Turbulent Mixing by Rayleigh-Taylor Instability, PhD Thesis, London University, 1986.

Bauer, R. A., The loss of natural moisture content of Pennsylvanian shale and effect on physical properties, Broc. Jllinois Mining Institute. 87th Annual Meeting, llinois Institute of Natural Resources, State Geological Survey Division, 13-28, 1980.

Bennett, R. H., W. R. Bryant, and G. H. Keller, Clay fabric of selected submarine sediments: fundamental properties and models, L.Sed. Pet., 51, 217-232, 1981.

Carter, N.L., and Hansen, F.D., Review -Creep of rocksalt, Tectonophysics, Vol. 92, pp. 275-333, 1983.

Carter. N.L., Kronenberg, A.K., Ross, J.V., and Wiltschko, D.V., Control of fluids on deformation of rocks, in: Knipe, R.J., and Rutter, E.H. (eds), Deformation Mechanisms, Rheology and Tectonics, Geological Society Special Publication N0. 54, pp. 1-13. Chandrasekhar, S., Hydrodynamic and Hydromagnetic Stability, Dover Publications, Inc., New York, 654 p., 1981.

Chenevert, M. E., and C. Gatlin, Mechanical anisotropies of laminated sedimentary rocks, L. Soc. Petrol. Engrs., 5, 67-77, 1965.

Chong, K. P., K. Uenishi, and A. C. Munari, Three dimensional characterization of the mechanical properties of Colorado oil shale, in: Broc, of the 20th U.S. Symp on Rock Mechanics, ed.

K. E. Gray, Univ. of Texas at Austin, 369-379, 1979.

Chorin, A.J., A Numerical Method for Solving Incompressible Viscous Flow Problems, J. Comp. Phys., Vol. 2, pp. 12-26, 1967.

Connell, S.D., and Stow, P., The Pressure Correction Method, Computers and Fluids, Vol. 14, No. 1, pp. 1-10, 1986.

Ghia, K.N., Hankey Jr., W.L., and Hodge, J.K., Study of Incompressible Navier-Stokes Equations in Primitive variables Using Incompressible Numerical Technique, AIAA Paper 77-648, 1977.

Gibbs, R. J., Error due to segregation in quantitative clay mineral X-ray diffraction mounting techniques, Amer. Min., 50, 741-751, 1965.

Handin, J., R. V. Hager, Jr., M. Friedman, and J. N. Feather, Experimental deformation of sedimentary rocks under confining pressure: pore pressure tests, Bull. Amer. Assoc, Pet. Geol., 47, 717-755, 1963. 
Harlow, F.H., and Welch, J.E., Numerical Calculation of Time-dependent Viscous Incompressible Flow of Fluid with Free Surface, Phys. of Fluids, Vol. 8, No. 12, pp. 2182-2189, 1965.

Hirsch, C., Discretization Methods for the Incompressible Navier-Stokes Equations, in:

Computational Fluid Dynamics for Industrial Flows, von Karman Institute for Fluid

Dynamics, Lecture Series 1990-04, 1990.

Hirt, C.W., and Nichols, B.D., Volume of Fluid (VOF) Method for the Dynamics of Free

Boundaries, L.Comp. Phys., 32, 201-225, 1981.

Homola, A. M., J. N. Israelachvili, M. L. Gee, and P. M. McGuiggan, Measurements of and relation between the adhesion and friction of two surfaces separated by molecularly thin liquid films, L. Tribology, 111, 6785-682, 1989.

Jackson, M. L., Soil Chemical Analysis-Advanced Course, Dept. of Soils, Univ. of Wisconsin, Madison, WI, 1956.

Jung, Y., A Solution Procedure for Incompressible Navier-Stokes Equations, PhD Thesis, The University of Texas at Arlington, 1980.

Klug, H. P., and L. E. Alexander, X-ray Diffraction Procedures for Polycrystalline and Amorphous Materials, J. Wiley and Sons, New York, 716 pp., 1954.

Kunze, G. W., Pretreatment for mineralogical analysis, in: C. A. Black (editor), Methods for Soil Analysis - Part 1. Agronomy, 2, ASA, Inc., Madison, WI, 568-577, 1965.

Lee, J. H., J. H. Ahn, and D. R. Peacor, Textures in layered silicates: progressive changes through diagenesis and low-temperature metamorphism, L.Sed. Pet., 55, 532-540, 1985.

Madsen, F. T., and M. Müller-VonMoos, Swelling pressures calculated from mineralogical properties of a Jurassic opalinum shale, Switzerland, Clays and Clay Minerals, 33, 501-509, 1985.

McLamore, R., and K. E. Gray, The mechanical behavior of anisotropic sedimentary rocks, L.Eng. and Ind Res., 89, 62-76, 1967.

Mehra, O. P.,and M. L. Jackson, Iron oxide removal from soils and clays by a dithionite-citrate system buffered with sodium bicarbonate, Clays and Clay Min, 1, 317-327 1960.

Nuesch, R., Das Mechanische Verhalten von Opalinuston, Ph.D. Dissertation \#9349, Eidgenössischen Technischen Hochschule (ETH), Zürich, 244 pp., 1991.

Nuesch, R., Experimental deformation of shale compared with natural features, in: Deformation Mechanisms, Rheology and Tectonics, ed. R. J. Knipe and E. H. Rutter, The University of Leeds, 1989.

Patankar, S.V., and Spalding, D.B., A Calculation Procedure for Heat, Mass and Momentum Transfer in Thre-Dimensional Parabolic Flows, Int. J. Heat Mass Transfer, Vol. 15, pp. 1787-1806, 1972. 
Peng, S. S., and S. Okubo, Prediction of in-situ stresses from directional properties of rock cores for field development of Devonian shales, EGSP Open File Report \#108, Morgantown Energy Research Center, Morgantown, W. Virginia, 74 pp., 1978.

Ramberg, H, Gravity deformation and the Earth's crust in theory, experiments and geological application, second edition: London, Academic Press, 452 p., 1981.

Shea, W. T., and A. K. Kronenberg, Rheology and deformation mechanisms of an isotropic mica schist, J. Geophys. Res, 27 (in press).

Smith, M. B., and J. B. Cheatham, Jr., A three-dimensional anisotropic yield condition for Green River shale, L.Energy Res.,102, 184-189, 1980.

Spiers, C. J., P. M. T. M. Schutjens, R. H. Brzesowsky, C. J. Peach, J. LO. Liezenberg and H. J. Zwart, Experimental determination of constitutive parameters governing creep of rocksalt by pressure solution, in Deformation Mechanisms, Rheology and Tectonics, (eds.) R. J. Knipe and E. H. Rutter, Geological Society Special Publication No. 54, pp. 215-227, 1990.

Van Eeckhout, E. M., The mechanisms of strength reduction due to moisture in coal mine shales, Int. L.Rock Mech. Min. Sci and Geomech. Abstr., 13, 61-67, 1976.

Woidt, W.D., Finite Element Calculation Applied to Salt-dome Analysis, Tectonophysics, Vol. 50, pp. 369-386, 1979. 


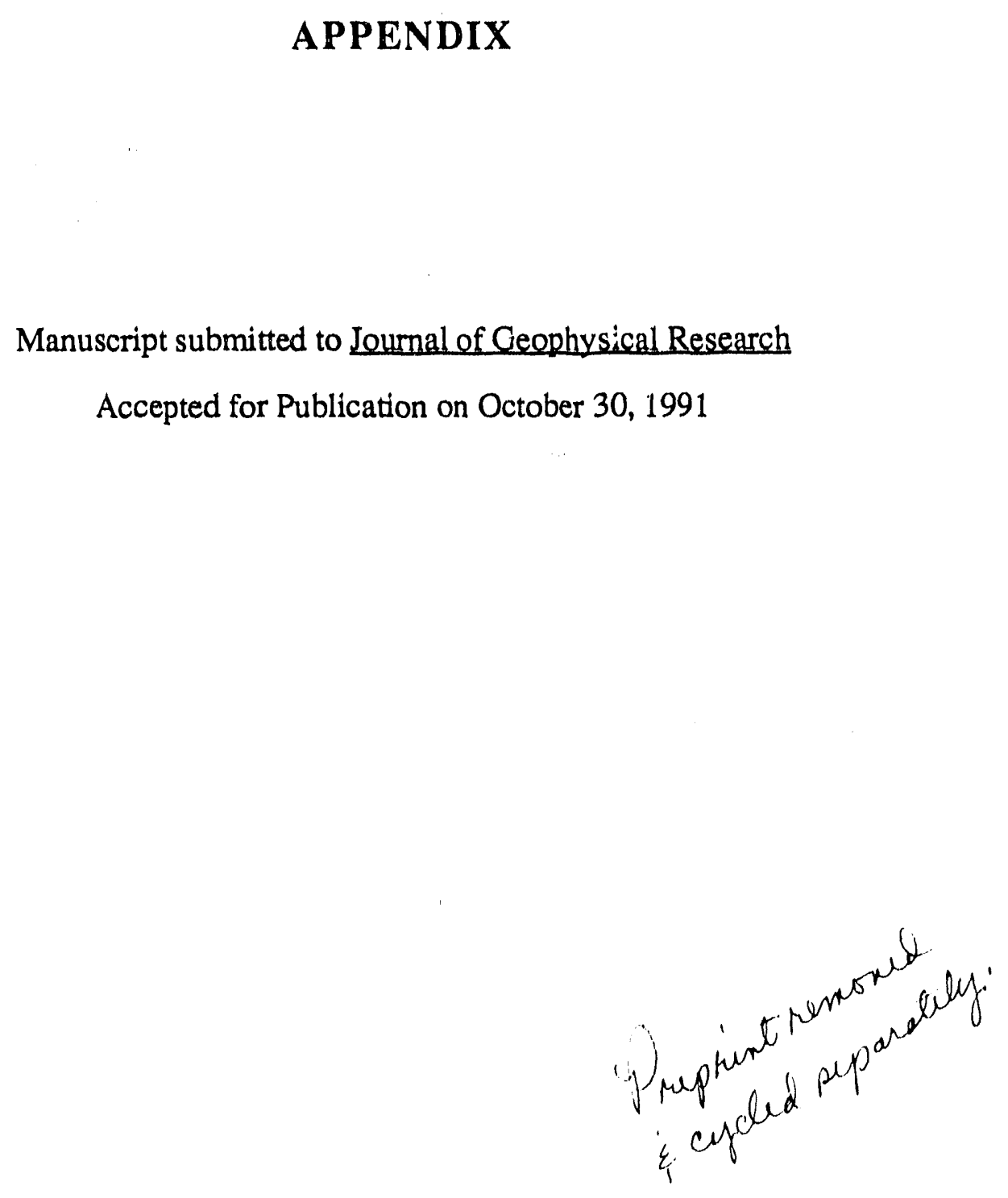



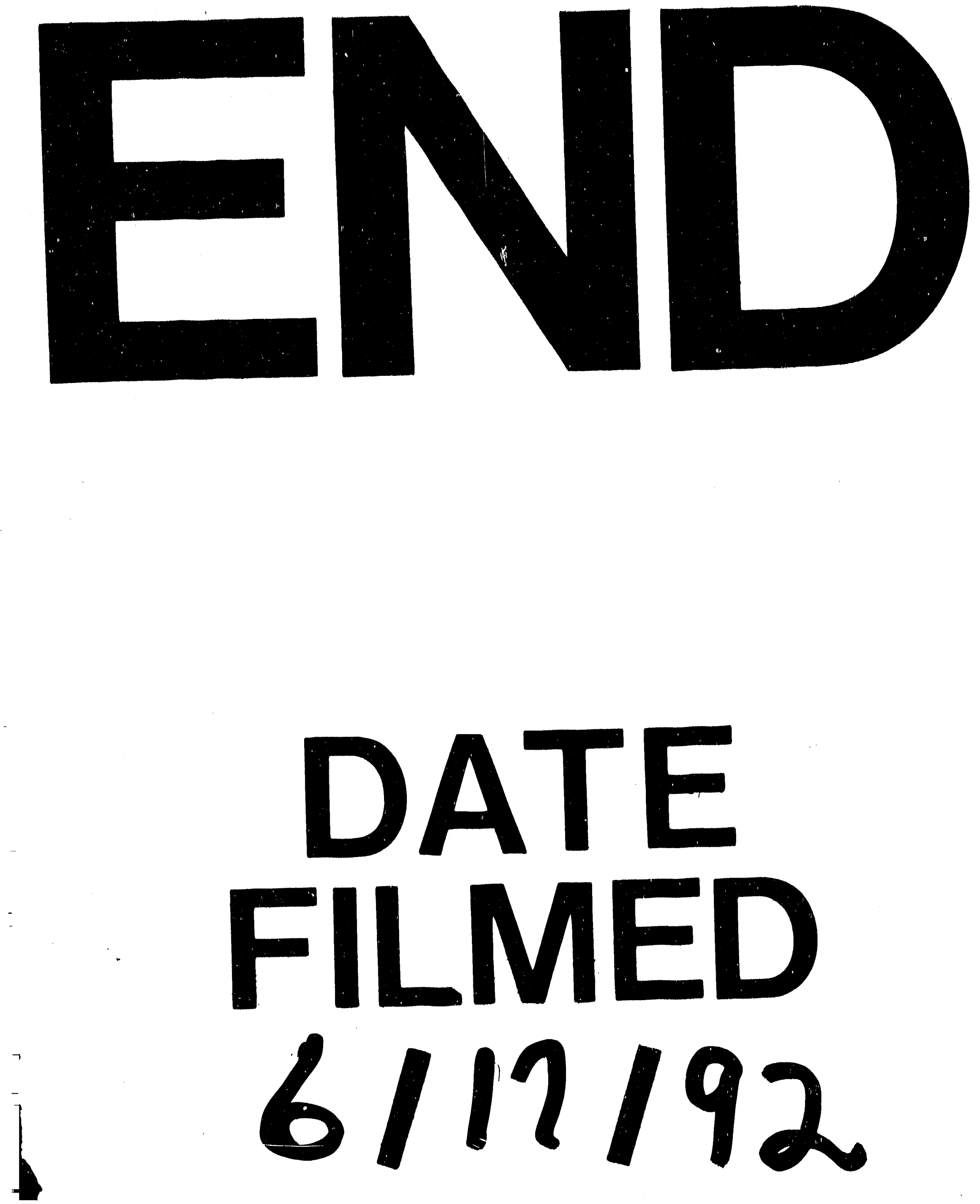
